\title{
My VRchive
}

Developing a Methodology for creating Immersive

Gaming Content and Interaction for Virtual Reality

By

Gerrit Jacobus van Rooyen

\begin{abstract}
A Masters Thesis by Portfolio
submitted to the Victoria University of Wellington in fulfilment of the requirement for the degree of Masters of Design Innovation in Media Design
\end{abstract}

Victoria University of Wellington

2018 

Please use the following link to access the digital experience for this thesis

\section{My VRchive}

https://gerritvanrooyen.wixsite.com/vr-masters2017-2018/ mastersthesis

Unless otherwise stated, all images included in this thesis were created by Gerrit Jacobus van Rooyen 


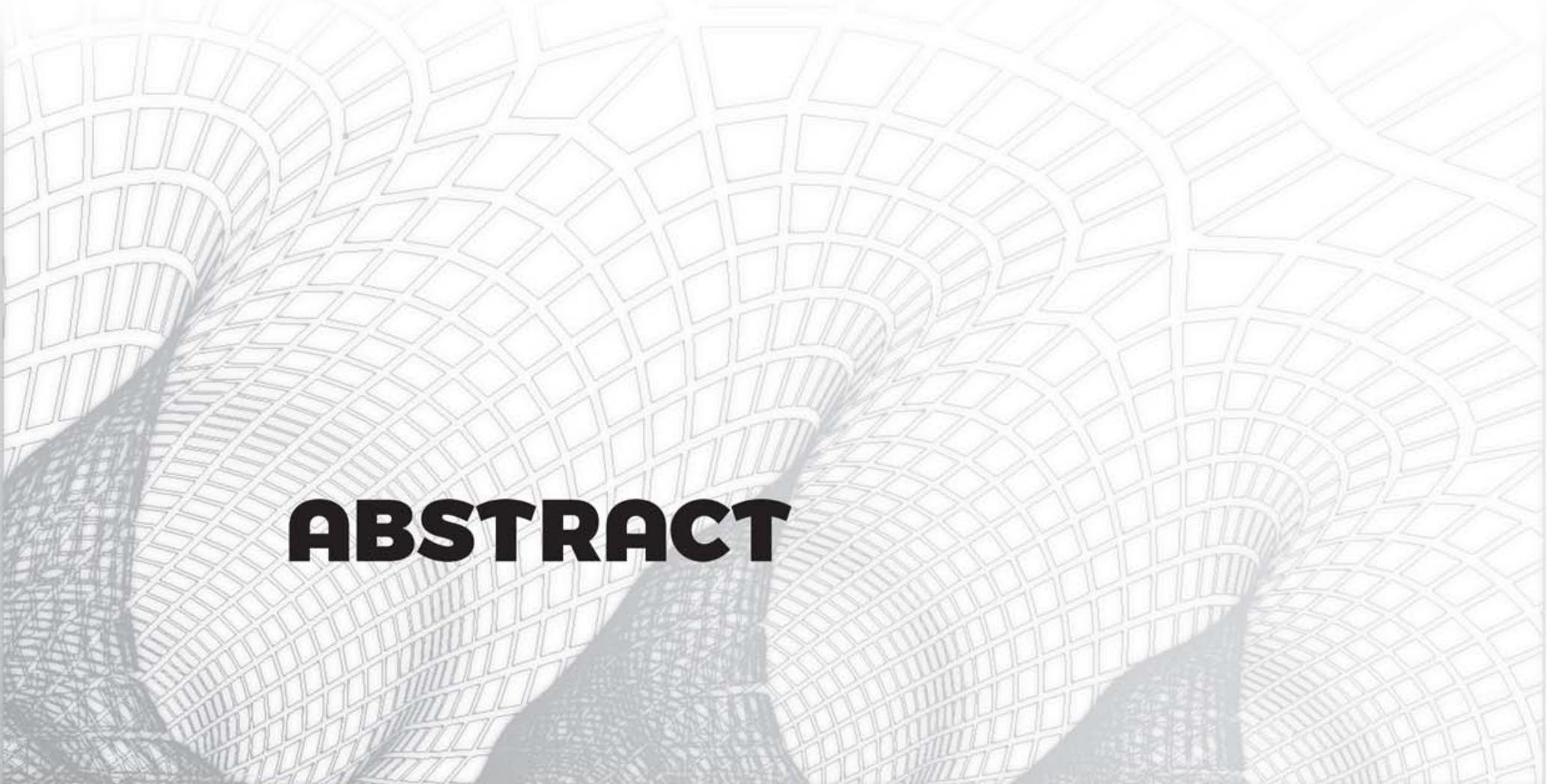




\section{Abstract}

Writing for and designing a methodology for Virtual Reality (VR) can be difficult as the technology around this medium grows at a fast pace. Many game designers and directors of VR experiences still claim to make things up as they go along, with no definitive methodology for content and interaction design existing yet. So far, some guidelines have been set to help prevent discomfort, but clearly not enough has been done to look at how and why we should design for VR specifically. As VR is a very immersive medium that can allow the user to potentially use their entire body as they would in the real world to interact with an experience, we need to take precedents from real world interaction when designing VR experiences. This thesis focuses specifically on game design and content generation by looking at board and table top elements as the realworld precedent. To demonstrate my findings, I have created an experience named My VRchive. Much like a sketchbook an animator uses to save ideas for later use, My VRchive will house small experiences created from my research, into content and interaction design, in a format that can be added to and shared. At the finalisation of this thesis three experiences were created. My theory is that if more designers adopt this strategy, we can all add to this growing methodology of how to develop immersive content and interaction for VR gaming and experiences. 


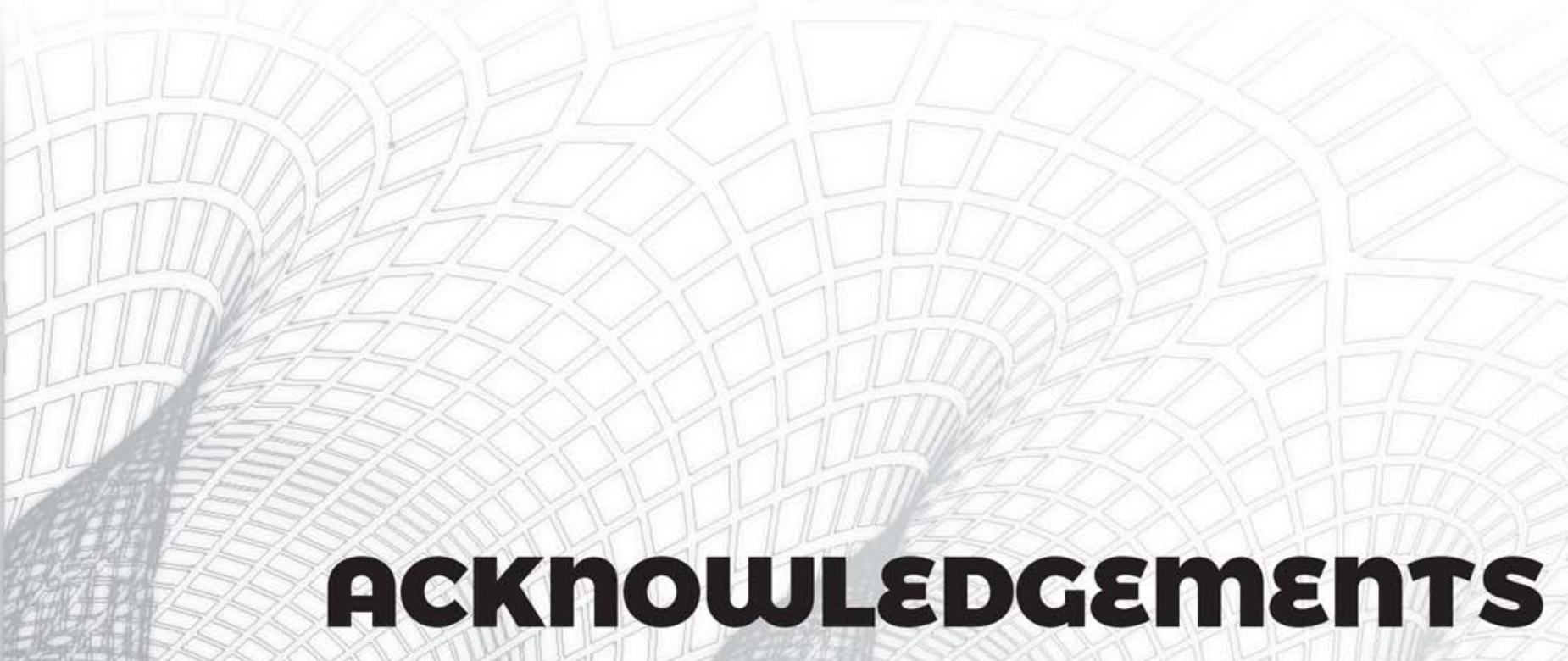




\section{Acknowledgements}

Without the following people I would not have been able to present his thesis to you today:

To my supervisors, Byron Mallett and Walter Langelaar, thank you for always being critical of my work. I respect your honesty which in turn gave so much clarity to what I had to do.

To Raqi Syed, thank you for your consideration in putting my name forward for the position at Wrestler. To the Wrestler team, thank you for making it the best place to work and for teaching me a lot about VR content creation and getting an ambitious project done in a short amount of time.

To my fellow Master's students, thank you for always having a kind word and being a safe place to bounce ideas around. Bryan, Phoebe, Sophie, Ivy, Tess, Chris, Mahkaila, and of course Stefan and Stefan, even though I mostly lived the life of a hermit and didn't see you all as much as I would have liked, you treated me like a friend and equal.

To the talented artists that selflessly contributed art towards my VR project, it is an honour to showcase some of your work. Ryan, Marike, Nicola, Shivashish, Chris, Fiona, Anna, and Jaco, I wish you all the best with your future work.

To my family, my Mother and Father, two brothers, and extended family here in New Zealand and around the world, whenever I needed you, you were there. You have given me more than I ever knew I needed. Thank you for the financial and emotional support.

To the one person who truly knows me, what it took to get through this, and who stood by me when even I did not want to go on, thank you, Diane. I can think of no greater honour and joy than to be your husband. 


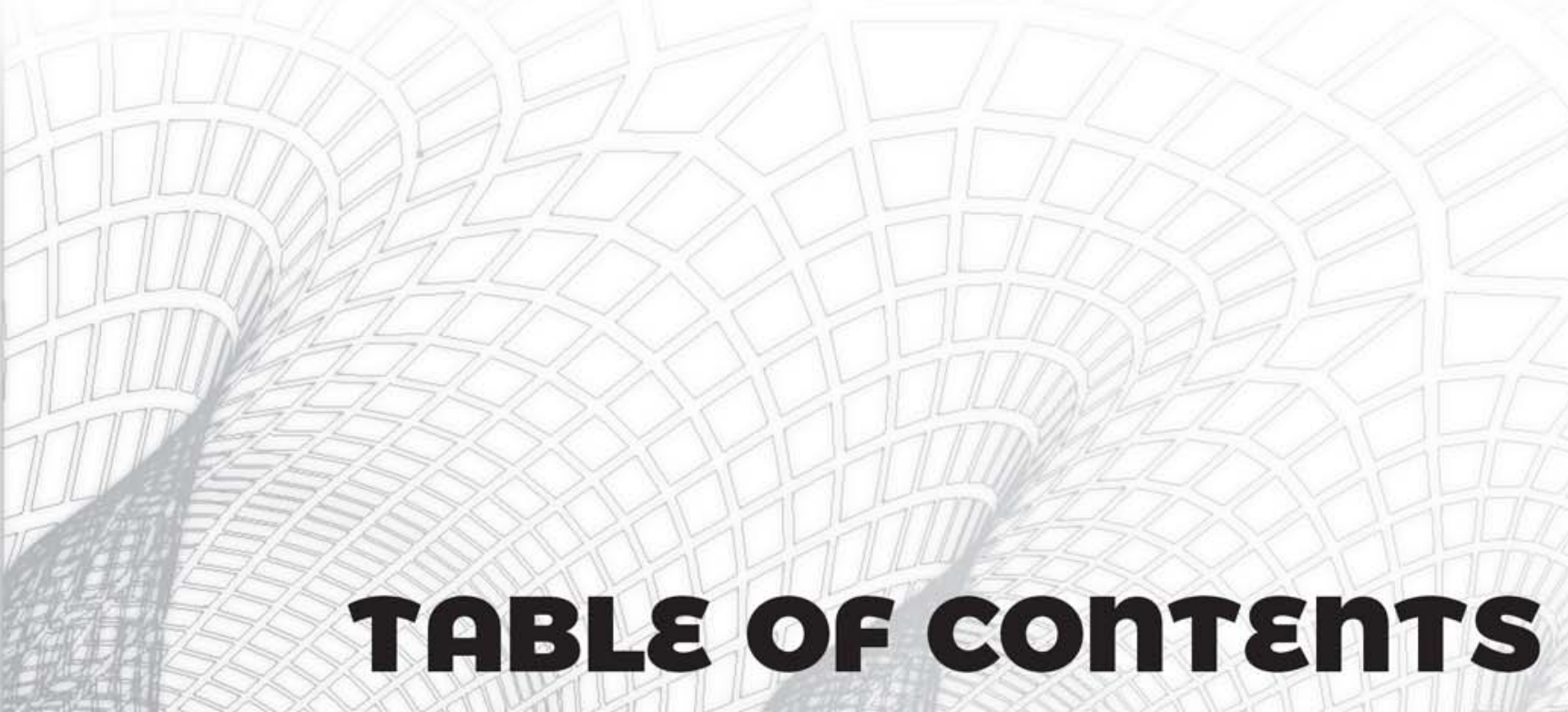




\section{Table of Contents}

\begin{tabular}{|c|c|}
\hline I. Abstract & 5 \\
\hline II. Acknowledgements & 7 \\
\hline 1. Introduction & 13 \\
\hline 1.1 Motivation & 14 \\
\hline 1.2 The Virtual World Around Us & 15 \\
\hline 1.2.1 Immersion and Presence & 15 \\
\hline 1.2.2 Sense of Scale & 16 \\
\hline 1.2.3 Object Handling & 17 \\
\hline 2. Research & 19 \\
\hline 2.1 Origins of Table Top and Board Games & 19 \\
\hline 2.2 Digital Gaming & 22 \\
\hline 2.3 The Interface & 23 \\
\hline 2.4 Proprioception & 25 \\
\hline 2.4.1 Object Handling and Interaction & 27 \\
\hline 2.4.2 Movement and Navigation & 28 \\
\hline 3. Context Studies & 31 \\
\hline 3.1 Virtual Table-top or Board Games & 32 \\
\hline 3.1.1 Tabletop Simulator & 32 \\
\hline 3.1.2 Brass Tactics & 33 \\
\hline 3.2 Thematic Games & 34 \\
\hline
\end{tabular}




\begin{tabular}{|c|c|}
\hline 3.2.1 Star Trek: Bridge Crew & 34 \\
\hline 3.2.2 Robo Recall & 35 \\
\hline 3.3 Proprioception Games & 35 \\
\hline 3.3.1 Beat Saber & 36 \\
\hline 3.3.2 Echo Arena & 36 \\
\hline 4. Design Experiments & 39 \\
\hline 4.1 Restrictions & 39 \\
\hline 4.2 Processes & 41 \\
\hline E1. Element Room & 43 \\
\hline E1.1 Prototype A: Element Picker & 43 \\
\hline E1.2 Prototype B: Element Combiner & 45 \\
\hline E1.3 The Final Build: Element Room & 47 \\
\hline E1.3.1 Notable Assets & 49 \\
\hline E2. Billy's Room & 51 \\
\hline E2.1 Prototype A: Possessing Chess Pieces & 51 \\
\hline E2.2 Prototype B: The Clone Pad & 53 \\
\hline E2.3 The Final Build: Billy's Room & 57 \\
\hline E2.3.1 Notable Assets & 59 \\
\hline E3. The VR Gallery & 61 \\
\hline E3.1 Prototype A: The Floor on a Floor & 61 \\
\hline E3.2 Prototype B: Points of Interest & 63 \\
\hline E3.3 Prototype C: The Blackout Wall & 65 \\
\hline
\end{tabular}




\begin{tabular}{|c|c|}
\hline E3.4 The Final Build: The VR Gallery & 69 \\
\hline E3.4.1 Notable Assets & 71 \\
\hline 5. Conclusion & 75 \\
\hline 5.1 Looking Forward & 78 \\
\hline 6. Bibliography & 81 \\
\hline 7. Appendix & 85 \\
\hline 7.1 Artist Contributions & 85 \\
\hline 7.2 Other Contributions & 85 \\
\hline
\end{tabular}




\section{Introduction}

This thesis presents my research findings and development towards a design methodology for creating immersive Virtual Reality (VR) interaction and content for gaming experiences. To achieve this, I want to encourage VR designers to keep and share examples of experiences they develop that is grounded in both research of VR's technology and real-world examples of interaction and content.

By using real world precedents for interaction and content design, specifically those found in table top and board games, I have developed a VR software package that houses three experiences that I can add to and use as guide for future projects. This package can also be shared with other designers to encourage them to do the same and therefore contribute to a larger methodology for designing immersive interaction and content for VR gaming.

The scope of this thesis will be limited to individual gaming interactions with some consideration made for multiplayer in a broader research sense. All experiences developed were single player experiences built for the SteamVR platform and HTC Vive specifically, created in Unity. All assets were developed by me unless otherwise stated. 


\section{$\underline{1.1 \text { Motivation }}$}

I have always had a passion for game design, especially in creating content and immersive elements. As a designer, it can sometimes be difficult to present your vision to an audience if the content and way the player interacts with your world does not naturally allow for learning of its interfaces and other gaming elements. Traditionally I was confined to working within the space of the single screen such as a PC monitor or tablet device. Over the years of game design, a methodology for working within this constraint evolved, with many writers compiling great books on the do's and don'ts of game design: The Art of Game Design: A Book of Lenses (Schell, 2014) and 100 Principles of Game Design (Despain, W., \& Acousta, K., 2013) to name but a few. VR changed a lot of this as the user was now placed much more functionally within the experience and I found myself excited to explore the design potentials of this new medium. With writers of VR content creation such as Jerald stating, "VR best practises are not yet standardized... nor are they mature" (Jerald, 2015 pp. 262), I feel myself drawn to adding to this body of knowledge so that myself and future game designers have all the tools to develop the best VR gaming experiences. 


\subsection{The Virtual World Around Us}

\subsubsection{Immersion and Presence}

The first and arguably most obvious difference with VR is that it has the potential to make the user feel like they are much more present in the experience. Mura explains in his book on Metaplasticity in Virtual Worlds that: "The fundamental and perceptible experience within these artificial environments is the sensation of 'Being There'" (Gianluca, 2010, pp. 6). He then goes on to quote Biocca who famously said "It [VR] isn't only a technology but it is a destination... [with the final goal being]...full immersion of the human sensorimotor channels into a vivid experience."(Gianluca, 2010, pp. 9). This is where, I feel, VR has great potential over traditional flat screen gaming.

With traditional screen gaming, the user must break through the distraction of the world around the physical screen to connect with the character and world they were playing in. Jerald, in his book on designing VR experiences with the human body in mind, has a great chapter on what immersion and presence means when it comes to designing for the virtual space. He explains that immersion can "lead the mind but cannot control the mind". Furthermore, that it is important to consider how we design the experience to use and match our senses, how the area around us is simulated as well as the interactions and story (or plot) (Jerald, 2015, pp. 45-46). For years now, designers have looked at VR immersion for more than just gaming. Studies have been done into Virtual Reality Exposure Therapy (VRET) sometimes known as Virtual Reality Immersion Therapy, showing the importance of immersion in VR. Compared to 
traditional therapeutic methods, VRET has proven to be as effective (Lamson, 1997)(Anderson et al., 2013)(Cukor et al., 2015)(Alsina-Jurnet, Gutiérrez-Maldonado, \& Rangel-Gómez, 2011)(Fuchs, Moreau, \& Guitton, 2011, pp. 85). Although outside the scope of this thesis, it does further solidify the importance of immersion in virtual environments.

\subsubsection{Sense of Scale}

The second, and an area where I feel most passionate about, is how we can experience scale in VR. Especially when playing first person perspective games, I always felt that I could not fully "be" the character I was playing as the difference in the scale of things around the screen interfered with the things I saw through eyes of my avatar. VR allows the user to truly feel the correct scale when looking at large but also small objects up close. I feel, that traditional screen methods just cannot translate this adequately. An experiment conducted by the University of Leeds had participants experience the same architectural recreation by walking around the virtual space either in VR or through a Desktop interface. What they found was that users in the VR scenario had a much better sense of space and scale compared to their Desktop counterparts. Their reasoning for this was that the VR version allowed for more natural head movement and attention (Ruddle, Payne, \& Jones, 1999). In my designed experience, "Billy's Room", I considered this by letting the user place toys on a mat and then transition to a larger version of the mat where they get to see the toys at a much larger scale and walk around them to inspect the large-scale toys up close. 


\subsubsection{Object handling}

For my final experience I looked at how VR can handle interaction with objects. This ability to allow the user to use their body more realistically to handle objects in the game world is something VR can do very well. This can range from picking up and placing objects to pushing buttons and pulling levers as well as just about anything we can do in real life. In more traditional flat screen gaming, users would use either a pointer device, keyboard or controller to target the objects and different muscle memory is needed to be developed to achieve this more effectively. Various studies have even been done over the years to show the negative effects on, for example the neck and shoulder muscles (Cook \& Kothiyal, 1998), to how we could hold the mouse and what effects the grip and size of our hands have on long term overuse strain (Agarabi, Bonato, \& De Luca, 2004).

In VR the controller becomes an extension of the user's hand forcing the player to engage with the world more in a way they would in real life. The technology to use proper VR gloves is in development with various companies trying to solve problems such as gestural input and feedback. Other companies are looking to use exterior cameras to map the user's actual hands and thus displaying a digital version to the user in their Head Mounted Display (HMD). By the time you read this thesis, they might have very well solved the problem of the perfect VR hands, which would open up even more possibilities for better emulating real world interaction. 


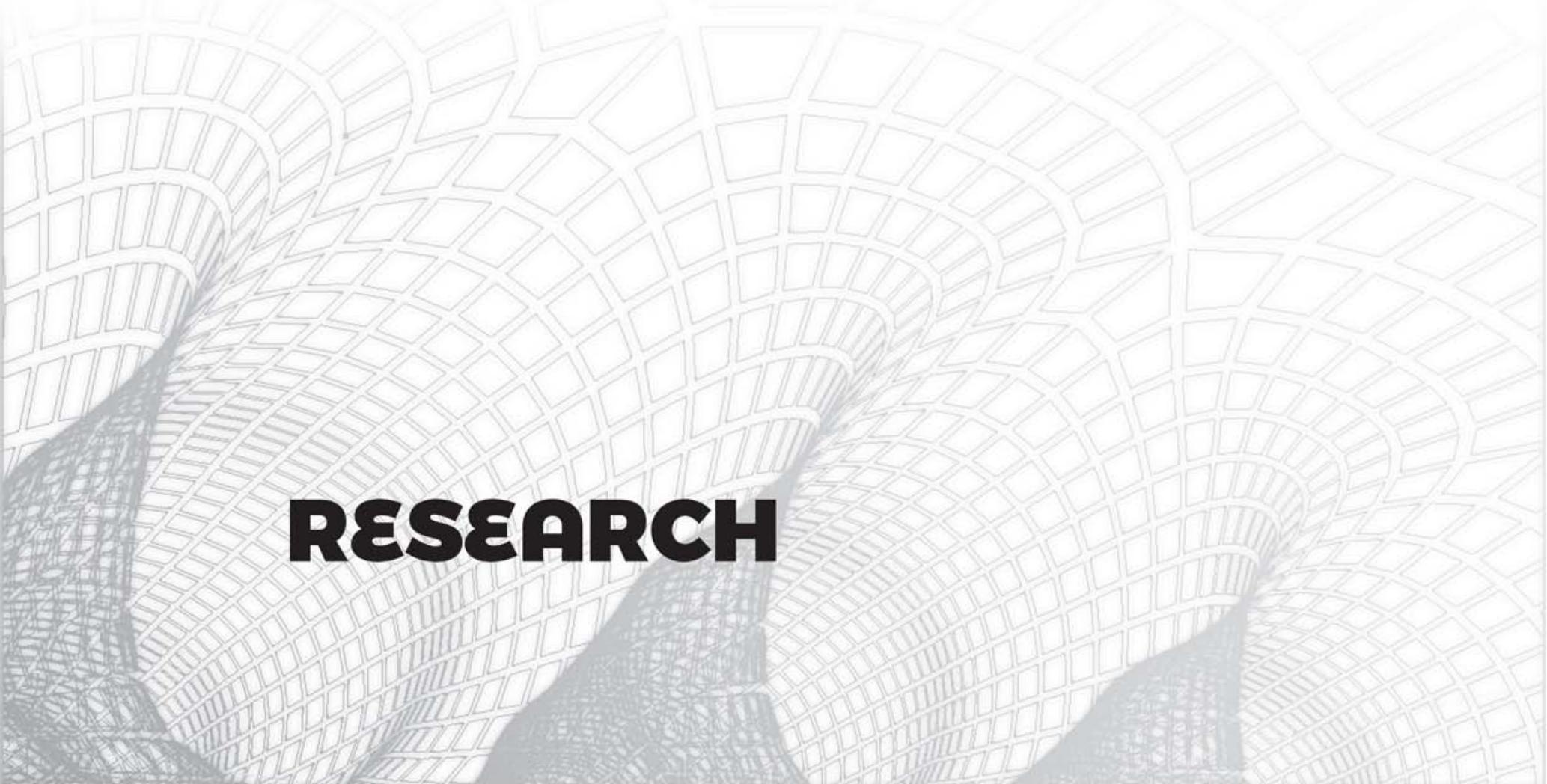




\section{Research}

\subsection{Origins of Table top and Board games}

I feel it is important to have a brief introduction to what I mean by table top and board games in the context of this thesis as I will be using elements from them as precedent for my contribution to My VRchive.

Most if not all of us have played a board or table top game in our lifetime. They have become a favoured pastime for gamers of all ages, with difficulties ranging from simple and taking only a short time to play to very complex and taking days or even weeks to complete ("The Notorious Board Game That Takes 1500 Hours To Complete," 2017). To back up my claim that we need to look at real world examples to build virtual ones, I needed to understand first how and why board and table top games were designed the way they were. To better understand these types of games I initially looked to the knowledge of three authors who seems to have established themselves as experts in this field. From their writing it was clear that board games were used throughout history as learning tools, entertainment as well as representations of real world processes. I must point out though, that they do not agree completely with each other on some of the finer classifications and origins. In fact, Parlett even claims that due to Murray's "pioneering work" other researchers have been invalidating his work, but was it not for his work, such research might not have been made (Parlett, 1999, p. x). 
Murray did however define Board Games quite clearly as: “All board-games are limited as to time and space. In time, they have a definite beginning and a definite end; in space, the action takes place within a definite area, that of the board, which is marked off beforehand, either materially or ideally, within which an absolute and prescribed order must be observed" (Murray, 1952, p. 5)

I am not going to reveal here too much of the history of board and table top games, instead I will tell you that these authors chose to classify the various types, as these classifications are something that is useful when designing a base for our own game experiences. My reasoning for this is that these classifications of games came from many years and cultures developing translations of real world events and interactions into gamified form, as we can see in the descriptions of the numerous games Murray, Parlett and Bell mention in their respective books. Even though most of the focus of each book was on how each game is played, there are various theories and claims made by the authors as to why.

Murray suggests that boards from as early as 4000 BC could have been used for divination instead of games even though they had the qualities of game boards and pieces found later (Murray, 1952, p. 13). Some boards found dating later than those were Sen't (or Senet) (Murray, 1952, p. 13) (Bell, 1979, p. 95), and the Sumerian Game (Bell, 1979, p.91) to name a few, dating between $3000 \mathrm{BC}$ and $1500 \mathrm{BC}$. Accompanying wall art and pieces suggest that these were indeed used as games, but no clear rules were found (Bell, 1979, p. 97). All three authors do however seem to agree that Senet was a race game (Murray, 1952, p. 18) (Parlett, 1999, p. 67) (Bell, 1979, p.97). 
The race game is just one of the types of games the authors suggest all board games fall under. Parlett has considered the classifications given by Murray and Bell and distilled the types into the following: Race Games, Space Games, Chase Games, Displace Games and Theme Games (Parlett, 1999, p. 9). The names are self-explanatory, but what is interesting is the evolution of some of them; suggesting why we play games have changed over time. We can see from the diagram on page nine of Parlett's book that Race and Space (originally classified as Alignment by Murray and Bell) stayed the same. However, War and Hunt type games evolved to Chase and Displace type games with Mancala type fusing with War and Hunt to become Displace. Parlett argues that Chase and Displace is necessary to adequately explain the evolution due to the increased amount of different games being created and creates a better blanket of identification than War/Hunt (Parlett, 1999, p. 12 - 13). Furthermore, the added category of Theme games, Parlett feels, better describes the majority of modern War type board games (and other themes) even though Murray dismissed the idea of Theme games as being pure chance games (Parlett, 1999, p. 9).

Stepping beyond classification, I was also interested in how board games are used to facilitate learning and competition. Most successful games and experiences consider either or both. Even though we might just want to make the game fun, usually that comes from either learning something, beating someone or challenging yourself. Gobet, Retschitzki, and de Voogt published a book in which they show the impact of research in board games for cognitive psychology. The authors present us with a list of studies in the fields of History, Social Sciences, Mathematics, and 
Philosophy, explaining that board games have been vital in multidisciplinary research over the years (Gobet, Retschitzki, \& de Voogt, 2004, p. 5). This further solidified my reasoning for choosing this type of real world interaction as inspiration for my designs.

\subsection{Digital Gaming}

For even a very casual digital gamer, it would not be hard to think of a different game to accompany each of the types mentioned by the authors Murray, Bell and Parlett. In fact, the goals for almost all games can be linked to one of those. There is an argument to be made for idle type games, ones where the real goal is arguably just to pass the time, (Khaliq \& Purkiss, 2015) although in my opinion this still falls under Theme type games. Therefore, it can be safe to assume that digital games too draw inspiration from real world events and goals. However, there is one fundamental difference between board games and non-VR digital games and that is how we interact with the game world.

In my introduction I made mention of some ways that users can interact with the digital gaming world. These tools were designed for users to interact with a flat screen, such as the computer mouse and keyboard. Even controllers such as ones used for gaming systems are primarily designed for reacting to and interacting with a game world that is presented to an external user looking at a flat screen. These input devices are used in a very different way from how we would handle objects in the real world. If we take the mouse, for example, the user 
moves the device on a flat surface to move a pointer on a screen that translates as a focus point for the character to move to or interact with. In the real world we would just walk there. Picking up objects with a mouse is also very different to physically grasping things with our real hands. It would be almost impossible to argue that flat screen gaming has been designed with these types of input in mind. Therefore, as designers we should be aware of this when taking precedents from flat screen games. There are, however some common ground when designing for VR and flat screen gaming. One important element that both share is the interface.

\subsection{The Interface}

One of the best explanations, to me, of the importance of interface in game design comes from chapter 15 of Jessie Schell's book on game design. "The goal of an interface is to make players feel in control of their experience" (Schell, 2014, p. 254). These words have always been important to me. When designing for games requiring an input device that was not naturally or ergonomically linked to the action, it can be difficult to create an intuitive interface. Schell further states "the ideal interface becomes invisible to the player letting the player's imagination be completely immersed in the game world" (Schell, 2014, p. 259). It is here that VR can truly shine.

Many games requiring a mouse, for example, forces you to first click on an object and then choose the action you would like to perform on that object. Typically, it would use some sort of virtual interface like a 
popup menu to do so. Many games have turned into a collection of these types of popup menu choices. Even though they work once you get to understand them, these interfaces tend to have nothing natural about the way you use them compared to the real world. VR has allowed the user to become so much closer to being part of that interface between themselves and the virtual world. This means game designers need to be so much more aware of how the human body interacts with scenarios in the real world when creating virtual ones. However, something that should not be overlooked is how the virtual world reacts back.

Schell claim that "experiences without feedback are frustrating and confusing" (Schell, 2014, p. 263) and that it is important to give some feedback to each action within as little as a tenth of a second! In my introduction I mentioned Biocca's comment about the human sensorimotor channels. Basically, sensorimotor actions are actions that evoke both our sensory and motor functions and is important to understand when designing for VR. The reason being that when we "push forward" in VR we expect to be "pushed back" just like in the real world. Fuchs writes in his book that it is important to understand that we are trying to get people to "perform a sensorimotor and cognitive activity in an artificial world"(Fuchs et al., 2011, p. 11), meaning that it would be beneficial to use real world precedents of interaction to influence our interface design for VR. Fuchs then goes to reinforce Schell's point by stating the importance of transparency of the VR interface (Fuchs et al., 2011, p. 13). The importance of considering sensorimotor actions branches out to many more areas within VR. Most of those, for now, are of more 
importance to Human Computer Interaction (HCI) designers of the technology that displays and allows us to interact with the VR world. Until we do not need HMDs and hand-held devices as part of the interface game designers will need to adapt to the new types of emerging technologies. These technologies are constantly being designed with the human body in mind and how it reacts to stimulus from the virtual world as it would in the real.

It is well known that the human body has a variety of senses that combine to help us understand the world around us. We smell, see, touch, and hear things around us and draw conclusions about this world based on experience or discover new ones. In this thesis I will not be going into too much of the intricacies of the human body sensory systems, but in terms of movement, interaction and immersion, designers need to be aware of certain points. One such area is the concept of proprioception.

\subsection{Proprioception}

In the real world our bodies sense change by a combination of our position in a specific space, how our body is moving based on muscle contractions, and any external forces exerted on us. This gives us the feeling of being immersed in our surrounding and is called proprioception (Fuchs et al., 2011, p. 76). For VR immersion this is particularly important as the human body becomes a frame of reference interface with the virtual world. As Jerald explains, designers of virtual worlds need to consider this. To illustrate, they use the example of being able to "place an object directly with the hand rather than through less direct means" (Jerald, 
2015, p.291). For most part, proprioception is something that occurs naturally in the real world, because we have grown up with these senses and learned from them. However, since we are introducing the user to a virtual world without having the tools to act upon the user as the real world would, we need to make sure not to conflict with user's natural proprioception (Jerald, 2015, p.105-106)

To illustrate the further power of proprioception in VR, an experiment done at the Eindhoven University of Technology found that they could make the user believe a virtual hand was part of their body. They did this by having the participant's own hand tapped and stroked outside of their view while simultaneously observing a virtual hand undergoing the same actions. Relatively quickly the participant created a physical bond with the virtual hand. They claim that this demonstrated an "intermodal correlation between vision, touch, and proprioception... illustrating that the body image is plastic", meaning that we can trick the body into believing what it sees is real, even attaching components (such as VR hands and noses) so long as they are designed in a way that aligns with our body's proprioception (IJsselsteijn, de Kort, \& Haans, 2006). 


\subsubsection{Object Handing and Interaction}

Until we develop fully haptic gloves and body suits, interacting and handling objects in VR might never feel like it does in the real world. However, through understanding of proprioception, designers can create experiences that mimic the body movements adequately enough to create immersive experiences without needing this kind of technology. As I will be limited to using the HTC Vive for this set of experiences, it is going to be important to work within these constraints.

Mura explains that interaction in VR is the key to presence, that it is essential for designer to illustrate the relationship between the user and the world. They also claim that the more vivid the experience, the more information can be relayed to the user to completely immerse themselves in the virtual world (Gianluca, 2010, p. 3 - 9), which after all is a goal for most game designers (Schell, 2014, p. 290).

To properly immerse our player in the game world, we need to consider the various "reference frames", as Jerald puts it. These consist of the Virtual World, Real World, Torso, Hand, and Eye reference frames (Jerald, 2015, p. 291 - 297). For now, these frames, apart from the Virtual World frame, require specialised sensors to transmit positional tracking to the program. This gives the designer the ability to attach virtual content to those reference points and interaction becomes possible. If these sensors are placed correctly and there is no noticeable lag in the data transmission, we can adequately emulate visual proprioceptive feedback to the player, resulting in much stronger presence and immersion. It then is up to the designer to create game mechanics to enhance the experience. 
A study conducted at the University of North Carolina at Chapel Hill shows the importance of using the idea of proprioception regarding interaction. They established that without the aid of haptics, convincing the user that they are touching objects in VR can be problematic. Their study shows several ways that the designer can consider proprioception when creating interaction regarding handling objects, interacting with menus, gestural actions, and some locomotive actions (Mine, Brooks, \& Sequin, 1997).

\subsubsection{Movement and Navigation}

For navigating a space in VR proprioception is particularly important for presence and reducing discomfort. An experiment by the University of London was done where they wanted to match the proprioceptive information they gained from the human body to the feedback from the VR space. They offered two options to the participants, walking in place ("Walkers") to move forward, or gestural pointing ("Pointers") and moving (Slater, Usoh, \& Steed, 1995). During their experiment, the authors found that two possible errors could occur during the Walkers' method. Sometimes the program would move without the action taking place or not move when the action did take place. What they found was that it was much more disconcerting to the participant when the program moved when it was not supposed to than the opposite. Meaning that when the body receives a miscommunication in terms of sensual input a lot more discomfort occurs than when it receives none when expecting it. What they did conclude was that overall, the Walkers experienced a better sense of presence in the Virtual World. 
Fuchs points to the discomfort (sometimes referred to as VR sickness) that can be caused when one of the senses overpowers another, in the case of movement, being vision and our body's expectation of movement based on proprioception. They do offer a suggestion that artificial external sensory stimulation could prevent this discomfort (Fuchs et al., 2011, p. 78 - 79). French authors, Plouzeau et al., conducted an experiment where they stimulated the "lower gluteus maximus muscles" during movement in VR through "proprioceptive vibrations" (Plouzeau, Paillot, Chardonnet, \& Merienne, n.d.). What they found was that the vibrations did not interfere with the movement (presence) and that it had a positive result in reducing VR sickness by as much as $47 \%$.

For the experiences that I develop to add to My VRchive, I am going to have to consider how far I am going to, if any, allow the user to walk around in the virtual space. Fuchs claims that to properly create an immersive movement experience we need to "stimulate all the sensory receptors required during leg movement in the real world" (Fuchs et al., 2011, p. 263). Seeing as I do not have access to an omni-directional treadmill, I will have to manipulate or constrain the walking area to around a few meters at any time. The types of interaction will depend on what the experience is trying to achieve and whatever interesting game mechanic I want to save for later use. All the above will be explained in the Design Experiments section of this thesis. 


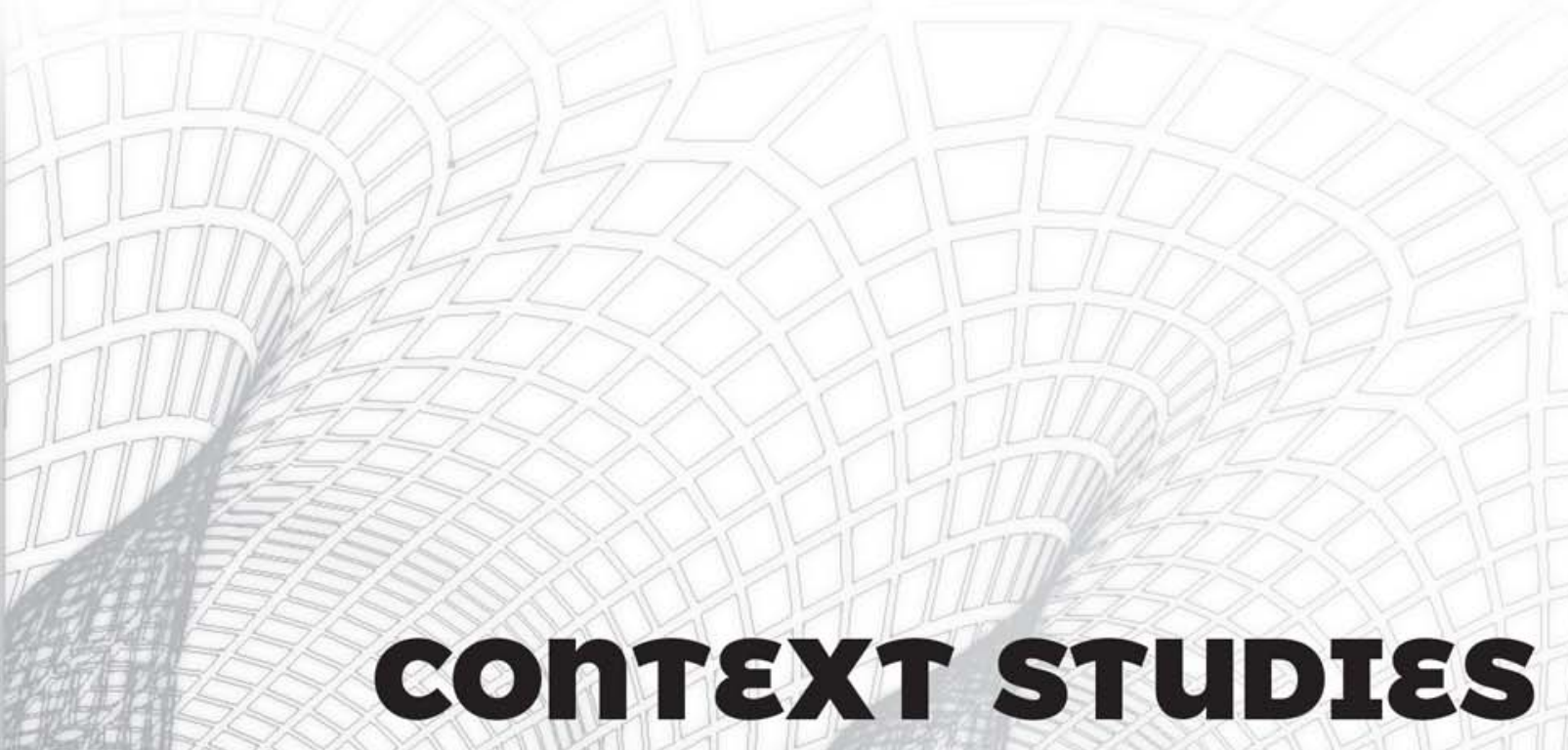

. 


\section{Context Studies}

To further my research and draw inspiration, I looked at some current examples of VR games that involved the elements I was exploring in my literature review above. As the games coming out are constantly changing due to advancement in the technology, it is impossible to say if many of these games are truly optimal for VR or if the audience just wants to embrace VR because it has become more affordable and commonplace. A blogger compiled some information about the amount of downloads of VR games and made a comment about how more popular independent (indie) developed games are over AAA (big production company) games ("Indie Devs, Not AAA Studios, Dominate Steam's VR Games Chart," 2018).

My theory is that AAA companies are still waiting until a formal methodology for creating VR gaming is developed before committing too many resources to new titles. A quick search of current AAA titles shows that there are indeed, subjectively, not that many available as of today ("Master List of All of the Upcoming And Released AAA Caliber VR Games," 2018). This could further mean that either players are simply downloading as many of the cheap (or free) indie titles as they can because they just want to experience as much VR as possible, or these indie developers have more freedom to create all kinds of fun mechanics and are essentially exploring the design potentials of the new medium. Perhaps both. 
For each section I will briefly name two chosen current examples with why I feel they are good precedents for my designs. I will provide a link to a webpage that provides video and images about the game.

\section{$\underline{3.1 \text { Virtual Table-top or Board Games }}$}

I chose the following two games because they had one important difference between them. With the first, the users are allowed much more control over the game area. They are presented with the board game of their choice and then must choose to follow the rules of that game as if it was the real world, not controlled by the program. The second is a much more thematic and rule-based game where the users must act within certain boundaries.

\section{$\underline{\text { 3.1.1 Tabletop Simulator }}$}

Tabletop Simulator, created by Berserk Games in 2015 (“Tabletop Simulator on Steam," n.d.), set out to create a VR space where the user could interact, as they would in the real world, with pre-designed table top games as well as user designed ones. The only rules the game developers enforce in the games are that of simulated gravity, physicality of objects, and game rules the user(s) set up.

With $93 \%$ of the 7,044 user reviews of this game being positive to date, it seems like people do find it enjoyable or at least intriguing. I found the sandbox feel of the experience quite entertaining and it inspired some 
of the ideas for my experiences. The ability to instantiate pieces at will as well as being able to pick up and inspect pieces up close are done well.

\section{$\underline{\text { 3.1.2 Brass Tactics }}$}

Released in 2018 by Hidden Path Entertainment, Brass Tactics, pits two players' armies against each other on a virtual table top map ("Brass Tactics," n.d.). Each player has a visible avatar and acts as their army's general, giving orders to units, building reinforcement structures at their base, and deploying all kinds of defences in the field.

Even though it is still early days for this title, Brass Tactics already has an $83 \%$ approval rating and the gameplay is quite smooth and fun. One thing I found innovative was the way the player could open up a menu at their hand, which took the form of a stand with a bunch of placeable objects. The player could simply pick one of these structures or units up and place them directly on the field, getting rid of clumsy popup menus.

Furthermore, I feel Brass Tactics' designers kept a well-crafted low fidelity steampunk theme throughout the game, which assists in having it run smoothly on even moderately priced systems. 


\subsection{Thematic Games}

Thematic games tend to focus on immersing the user in either a recognizable or new fantasy world to experience something from the perspective of a character they would normally not be able to. The first game chosen puts the user in the avatar of a character from a well-known show and the second a sandbox style story game. Each manages to create a good sense of presence.

\subsubsection{Star Trek: Bridge Crew}

Star Trek: Bridge Crew, developed by Ubisoft and Red Storm Entertainment in 2017, lets the user take on a series of roles aboard a federation spaceship from the popular TV series, "Star Trek"T" ("Star Trek $^{\mathrm{TM}}, "$ n.d.). Players can experience various scenarios by themselves or as a team of real world players, interacting with the various ship interfaces to make decisions together and overcome obstacles.

The game has an $83 \%$ approval rating currently with most of the negative comments being technical issues that seems to stem from the player's side, such as internet connection and microphone issues. Communicating with your team mates is very satisfying and coming up with solutions to problems together even more so. The various touch interface are reactive enough to allow for a strong sense of immersion, although sometimes there were some issues with collision detection. Animations for the hands and snapping of picked up objects are done well, and it was great to see full body animation with only the headset and hand sensors as reference. 


\section{$\underline{3.2 .2 \text { Robo Recall }}$}

Robo Recall, developed by Epic Games in 2017, puts the player in the shoes of a tech repairman investigating some defective service robots in a futuristic scenario ("Robo Recall," n.d.). This was one of the first VR games I experienced, and I still remember the moment in the opening sequence. You are surrounded by robots, just before they turn evil, looking at news on a set of tv screens outside, only to have them turn to you and attack suddenly. That moment showed to me just how immersive the VR world could be and was one of the reasons I started looking into VR research.

Even though this is a simple, teleport movement based, shooter game, the animations are very fluid, object handling feels natural and there is plenty of visual feedback to make you feel like you are present in the scenes. The graphical fidelity is also very consistent, with well designed levels and detailed models, all adding to the immersion for the player.

\subsection{Proprioception Games}

I chose two games to show off the effectiveness of considering proprioception in VR games. The first is a brand-new game that is incredibly simple but utilizes the human body by referencing an old arcade style of gaming. The second was the game, introduced to me by my supervisor, that made me think about proprioception originally. 


\section{$\underline{\text { 3.3.1 Beat Saber }}$}

Beat Saber, developed by Beat Games in 2018, is a rhythm style game that lets the player use their entire body to perform in VR ("Beat Saber on Steam," n.d.). Much like the arcade dancing games from the late 1990 's, Beat Saber has the player moving to the beat of a song. What makes Beat Saber different is that the two controllers translate to two light sabers in-game, one red and one blue, that the player needs to use to hit red and blue arrows as they approach. Miss too many or stand in the wrong spot as a wall of energy passes by and you risk failing the level.

Beat Saber is sporting an incredibly strong $98 \%$ approval rating over 4,463 reviews to date, with only slight technical issues and small song selection being the only concerns. The game has simple controls, with the game being easy to play but hard to master, the golden rule for most game designers. I feel the real success with this game is that it allows the user to interact with the VR world as they would in the real world, encouraging dancing to the beat and hitting virtual objects while ducking out of the way of obstacles. Even though the developers did not design things like levers or other objects specifically for the player to use proprioceptively, the designers created a way for the player to naturally move as they would in the real world.

\subsubsection{Echo Arena}

Echo Arena, developed by Ready at Dawn in 2017, is a zero gravity sports experience set in the future where two teams face off against each other to throw a disc into the opposing team's gate ("Echo VR," n.d.). 
As I mentioned before, Echo Arena was introduced to me by my supervisor and the second VR experience I tried. What struck me was how my supervisor moved when interacting with the virtual world. In this game you can grab onto things and pull yourself forward and use wrist mounted propulsion to stabilise and do small movement adjustments. When grabbing onto the edge of an object and pulling towards yourself, you would propel forward, much like you would in a real zero gravity scenario. I noticed my supervisor going through the entire body motions of curling up the shoulders, ducking the head slightly, all to prepare for the upcoming "movement". Naturally, just flicking your wrist in the right direction in the real world would translate to the same action in the virtual world, but he went through the natural movements anyway. When I asked him about this, he stated that he did not even know he was doing it, but that it felt right to him to do so. When I tried without employing these natural movements, I noticed that I would experience discomfort. Moving naturally drastically reduced this.

I feel that Echo Arena is a great example of how designing experiences that allow the user to naturally utilize proprioceptive senses in the body is successful at creating a better game experience. 


\section{DESIGn EXPERImEnTS}




\section{Design Experiments}

In the following section I will explain how I created each of the three experiences for the first entry for My VRchive. I will explain what each experience is about, followed by some prototypes developed to get to the final build, and notable asset created.

\section{$\underline{4.1 \text { Restrictions }}$}

Jonathan Linowes offers an important question about writing about VR today: "How does one write a book [or paper on VR] that does not have obsolete content the day it is published?" (Linowes, 2015, p. 9) The reason for this is that the development of VR technology and therefore the design possibilities that follow, are growing at such an exciting rate right now that to make any kind of observation or point we need to explain the restrictions we had when we wrote about or developed an experience. These restrictions are not just around the VR technology such as Head Mounted Displays (HMDs) etc., but as we are talking about game design, we need to think about the software packages we are using to create content, the engine we are using to develop the game in as well as the size of the team and time we have available. For each experience, as with all game design, we need to also consider our target audience. I have developed my first three My VRchive experiences with the following restrictions in mind. 
Restrictions - cont.

\begin{tabular}{|c|c|}
\hline Technology & Details \\
\hline PC & $\begin{array}{l}\text { Intel(R) Core }{ }^{\mathrm{TM}} \text { i7-7700 CPU @ } 3.60 \text { GHz } \\
\text { 16.0 GB Installed Memory (RAM) }\end{array}$ \\
\hline Display Adaptor & $\begin{array}{l}\text { Nvidia GeForce GTX } 1070 \\
8 \text { GB Graphics Memory } \\
8 \text { GB Shared System Memory }\end{array}$ \\
\hline Operating System & $\begin{array}{l}\text { Windows } 10 \text { Home } \\
\text { 64-Bit Operating System, x64-based processor }\end{array}$ \\
\hline Virtual Reality Gear & HTC Vive \\
\hline Platform & SteamVR \\
\hline Content Development & $\begin{array}{l}\text { Autodesk Maya LT } \\
\text { Allegorithmic Substance Painter } \\
\text { Adobe Photoshop CC }\end{array}$ \\
\hline Game Engine & Unity Technologies' Unity \\
\hline Coding & $\begin{array}{l}\text { Microsoft Visual Studio } \\
\text { C\# (Language) }\end{array}$ \\
\hline
\end{tabular}

Audience: General gamers, general public, VR enthusiasts.

Team size: 1 - Gerrit Jacobus van Rooyen 


\section{$\underline{4.2 \text { Processes }}$}

As discussed before, there are many components that need to be designed correctly to create an immersive experience in Virtual Reality (VR). I decided on the following three areas to develop experiences for: Sense of Scale, Navigation, and Object Interaction. Each experience will naturally have elements of each three but will focus on a specific one as explained in their introduction.

I started developing a series of prototypes that would ultimately turn into the three designed experiences I present with this thesis in my first My VRchive entry. In the following three segments, I will explain the process each experience underwent to achieve their result. This consisted of a prototype phase, an asset generation phase and the final build phase.

A downloadable standalone version of My VRchive entry is available through the links provided at the start of this thesis, so you can experience it for yourself. User specifications will be included as a text file with the executable files. 


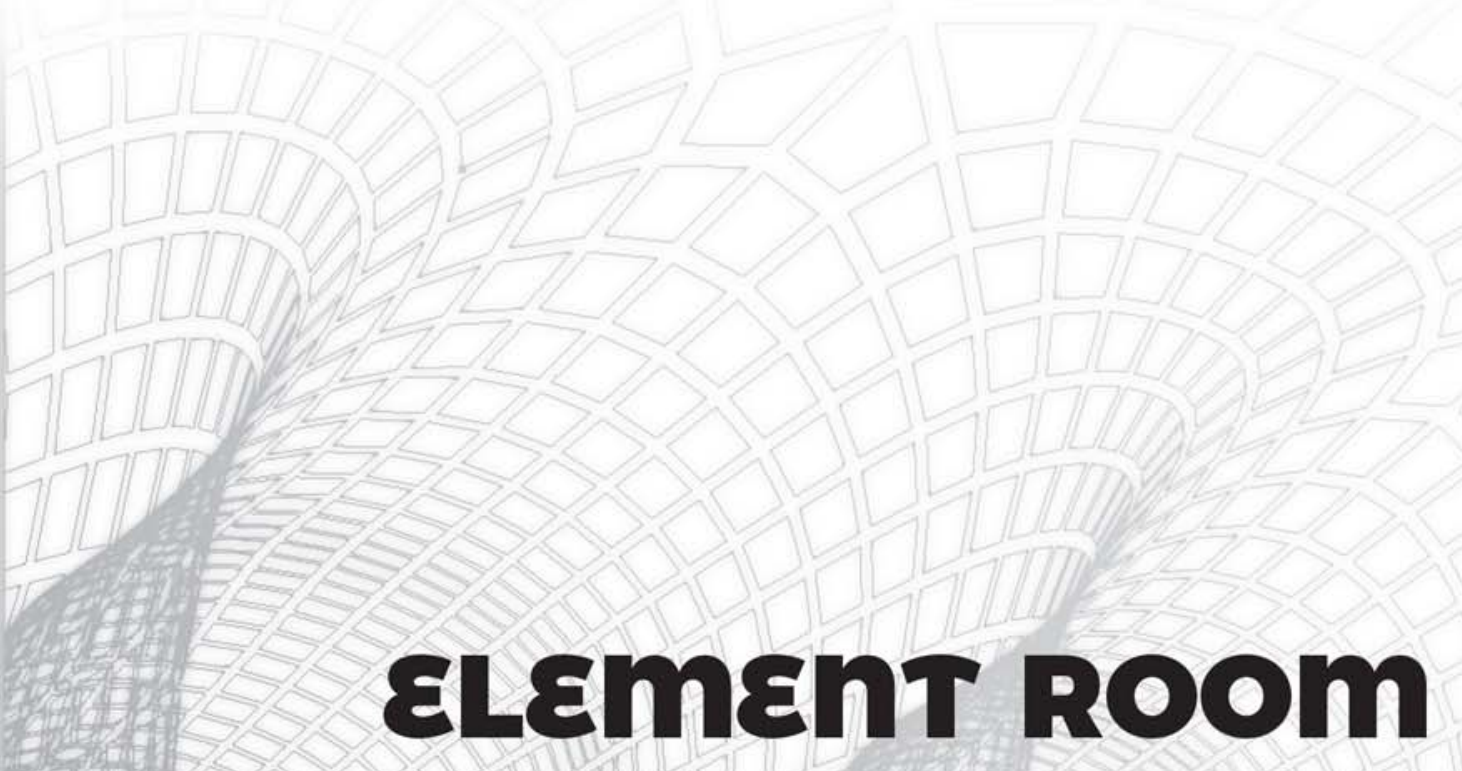




\section{E1. Element Room}

The Element Room focuses on the idea of learning and interaction that is possible through gaming experiences. As mentioned before in my research on board games, many cultures used games as learning tools or as representations of real world processes. I wanted to create a simple game that would be both motivated by the periodic table and puzzle solving. I also wanted to work with the idea of combining objects through interaction in the virtual space and feedback as reward.

\section{E1.1 Prototype A: Element Picker}

I needed to figure out a way to incorporate the periodic table of elements into my game scene and have the user be able to pick elements from it.

To achieve this, I first designed a simple periodic table of elements image in Photoshop. The image was 2048 x 2048 pixels in size. I then mapped the $x, y$ coordinates of each of the element squares on the image and stored them in a Coordinates text file.

For the coding I created a simple code that would fire a ray from the user's hand (when the trigger button was held down of the controller device). From there I create a code in C\# that would be able to receive the $x, y$ coordinate point data from the 2D map of the albedo channel of a material the user would points to. If the user was pointing to an object 
Element COMBINER
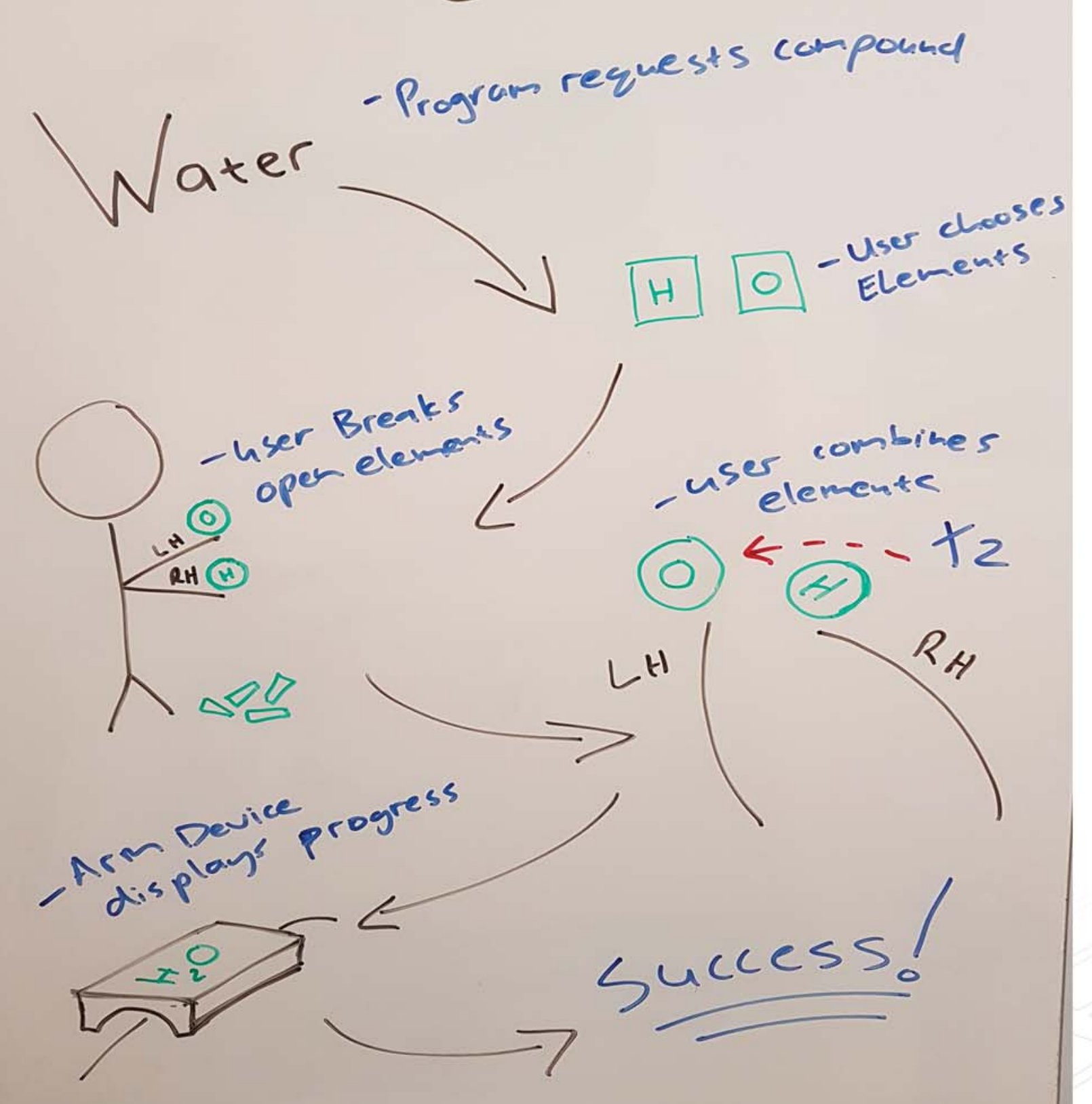

Fig. 2: Element Combiner Prototype planning 
who had a material that contained the albedo map of the periodic table, the coordinate the user was pointing to would be compared to the values in the Coordinates text file. If the coordinate falls within the range of one of the elements on the image, the code would return the name and anatomic number of that element.

From there I would instantiate a copy of the correct 3D model, based on the number returned (out of 118 possible element models), and place it in the user's hand. The user could then look at it and drop it by releasing the trigger button. These 118 elements were created by modelling a cube object in Maya which was then textured in Substance Painter. To achieve this, I had to create an image for each six sides of the cube to show six pieces of important information about that element: Name, Atomic Weight, Atomic Number, Valence Shell Diagram, Symbol, and Classification. From those images I then created the textures for the cubes.

Essentially pulling objects from a flat surface based on what you choose on the image was exciting and very satisfying.

\section{E1.2 Prototype B: Element combiner}

Following the success of the previous prototype, I wanted to figure out a way to combine the elements in an interactive way. The solution was quite simple but proved to be fun to play with.

Extending prototype A, I created script that would ask the user for a compound, for example water. The user would then have to choose the 


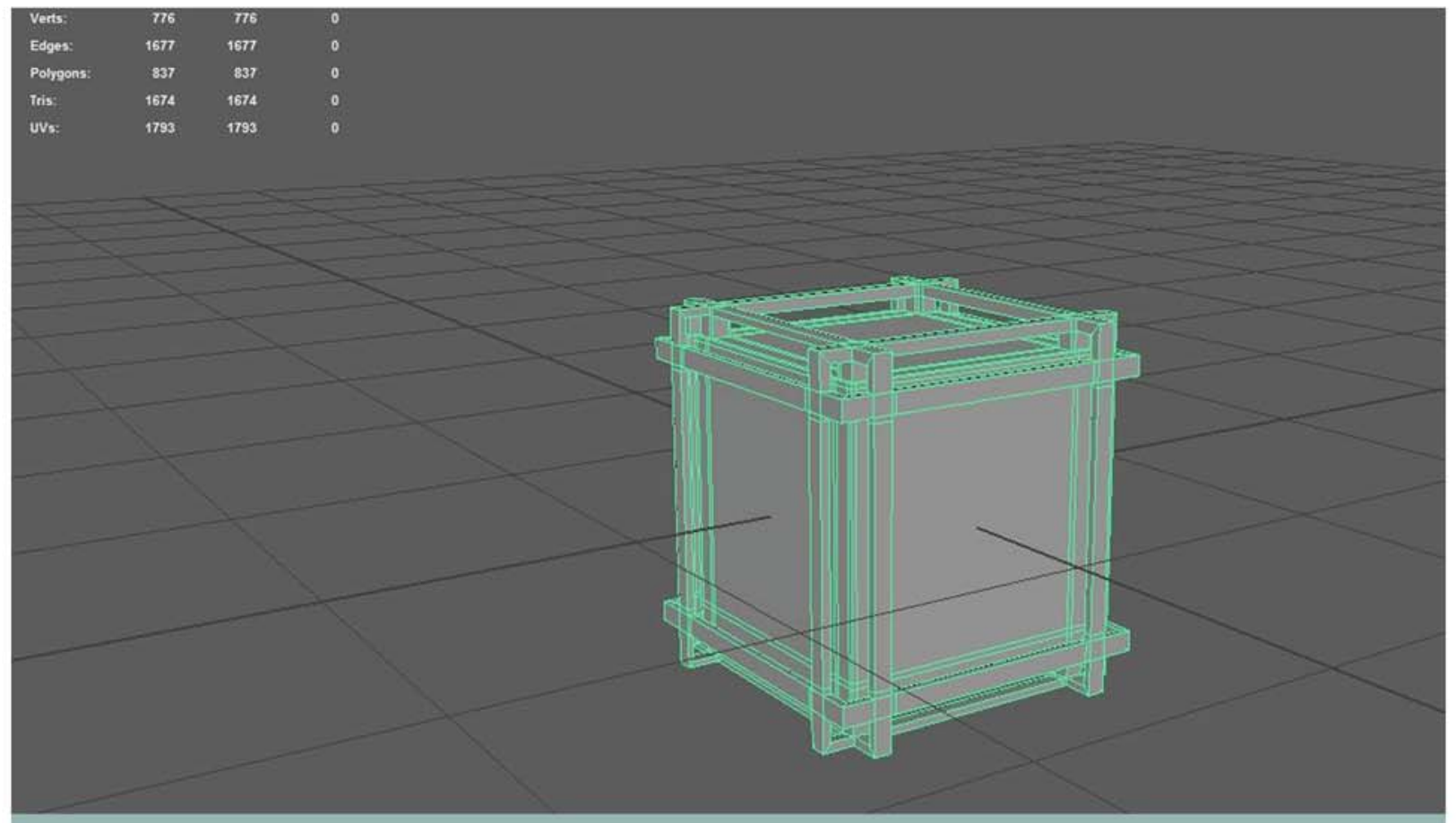

Fig. 3: Creating the 3D element cube

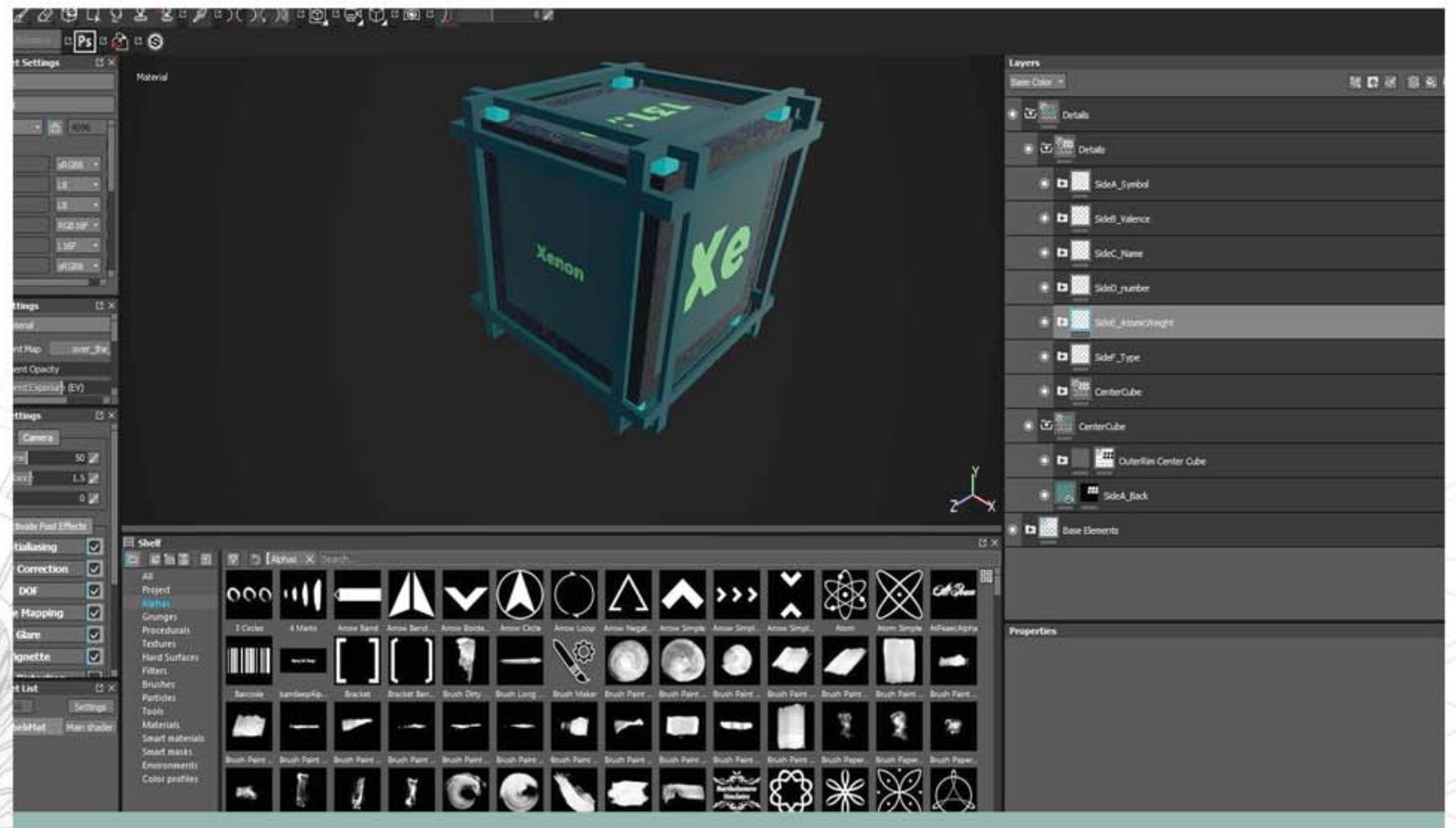

Fig. 4: Creating the texture maps for element cubes 
first element with one hand and squeeze the grip on the side of the Vive controller to "break open" that element, essentially locking it in as a choice. The user could then choose a second element with their other hand, squeeze it to break it open and add it to the first. If the user adds the correct elements in order, the compound was created and the program would congratulate the player.

To achieve this, I had to create a simple sphere with the elements symbol on it to represent the held element. I also created a User Interface panel for the arm device that would display the current line of elements added to the original one. Lastly, I needed a way to show the element holding box breaking open, so I took the model of the element box and separated it into 4 pieces in Maya. Once the user broke open an element I simply replaced the original box with the four pieces that would fall from the player's hand and leave behind the element sphere instead.

What was interesting was that most people I showed this to enjoyed breaking open the elements more than combining it. I feel this is because the feedback of the box breaking open and the new element being revealed was done well, reinforcing what Schell said about feedback in games.

\section{E1.3 The Final Build: Element Room}

For the final version of this experience I wanted to create a gamified version of the previous two experiences. For this, I created an octagonal room with a slight sci-fi futuristic theme to it. Each of the walls would look similar, apart from one, which would have the periodic table of 


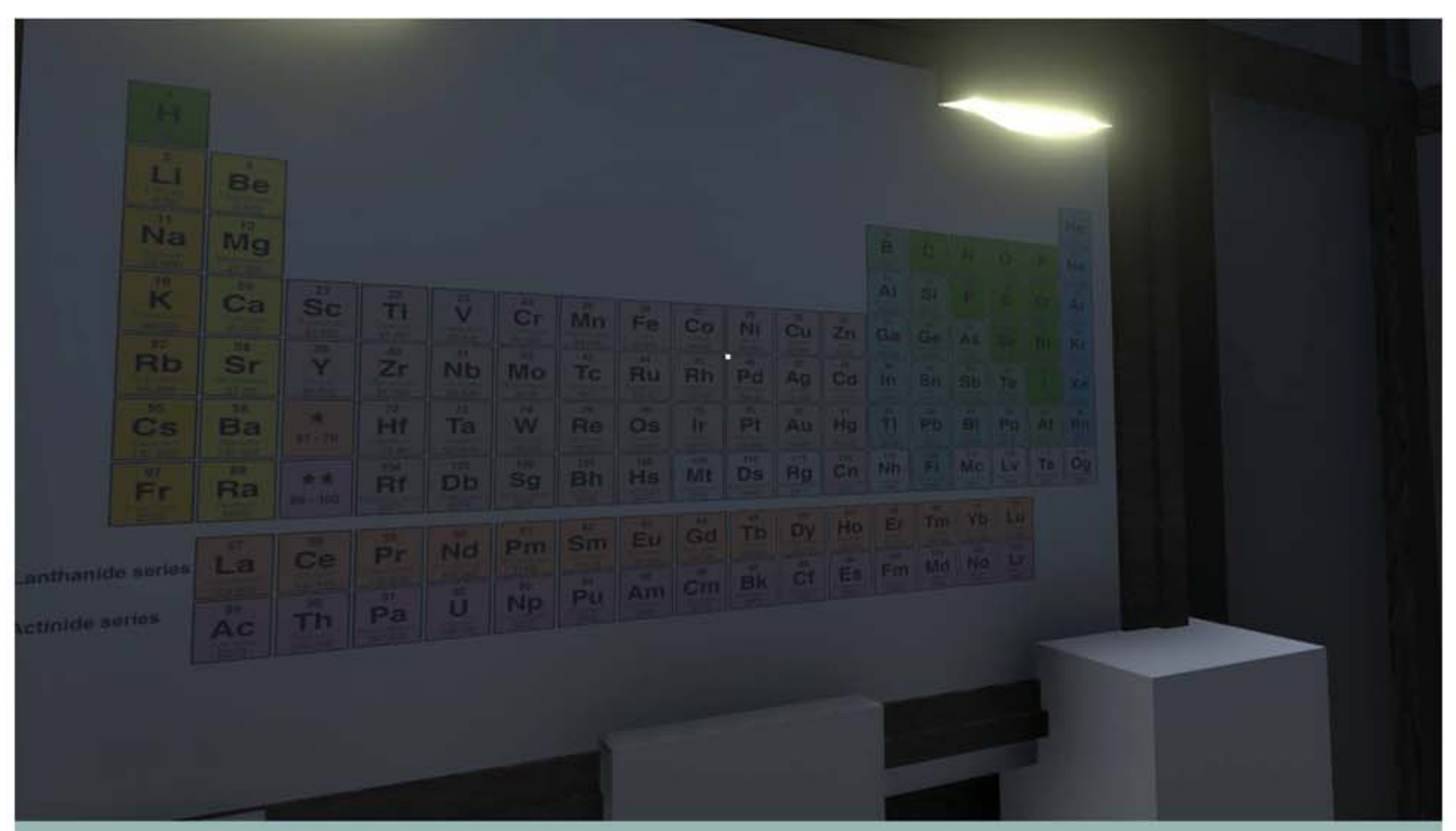

Fig. 5: Element Room : Periodic Table wall

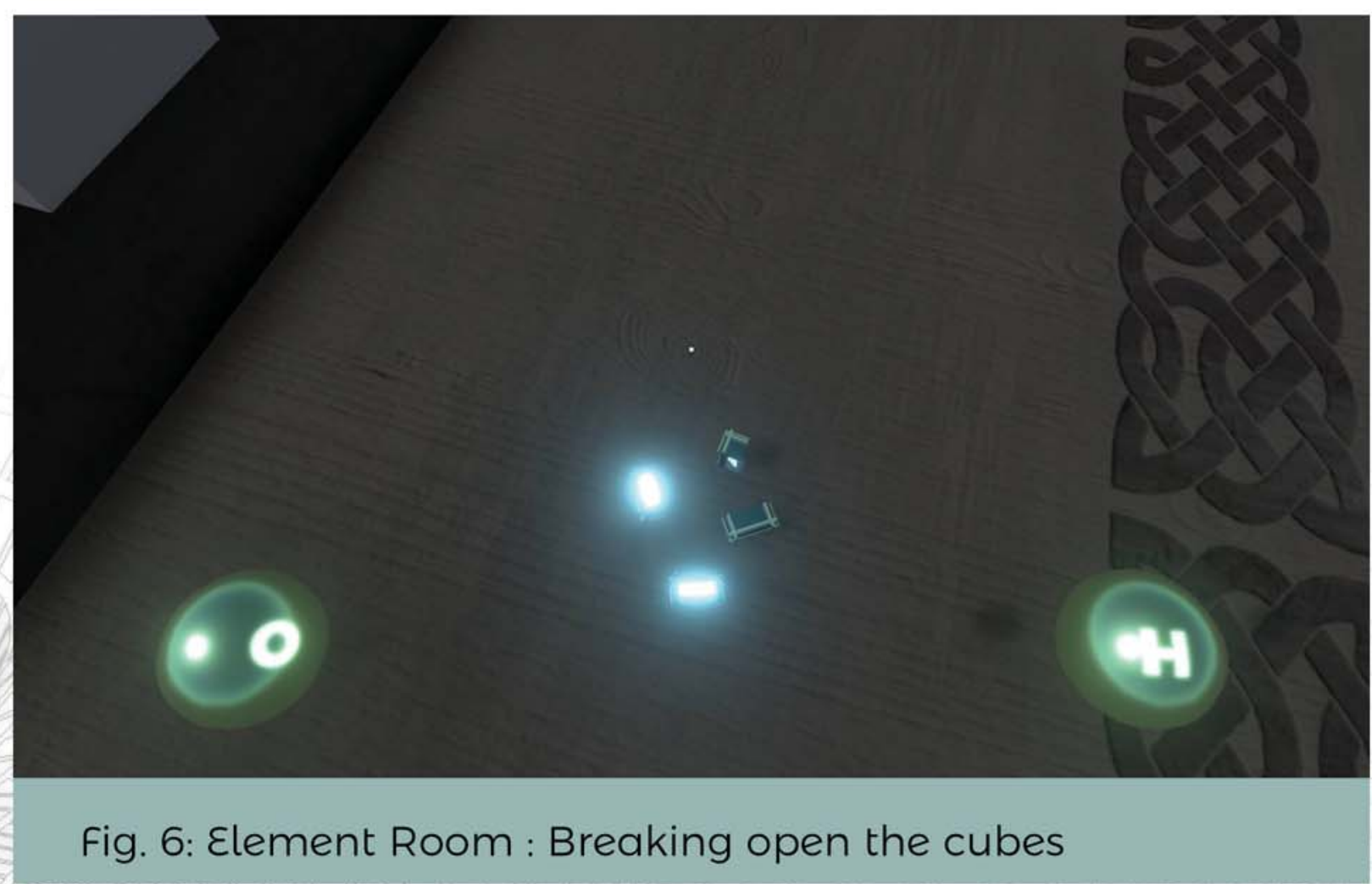


elements panel against it. Each of the other walls would have an image that would give the user a clue about what they needed to create.

Just like with the previous prototypes, the user could point at the periodic table on the wall and choose an element. This time, the element would fall at the user's feet instead. The user would need to pick it up and break it open to choose that element. The user can then proceed to throw the element at any of the walls. If that element is part of the compound the wall would accept it and add it to the sequence. Once a sequence is complete, that wall would be solved and reveal a hidden object. Basically, just a physical representation of that compound.

I feel this experience shows what I wanted to achieve with it. A user can learn a bit about chemical compounds and even properties of the elements by looking closer at them. Handling the objects and seeing the feedback from interacting with the environment was satisfying as well.

\section{E1.3.1 Notable Assets}

What was great about building this experience was that I already had most of the assets built. The periodic cubes and parts took me weeks to complete for the prototypes, so I was happy to be able to reuse them. The only additions were the thematic decorations placed around the level. 


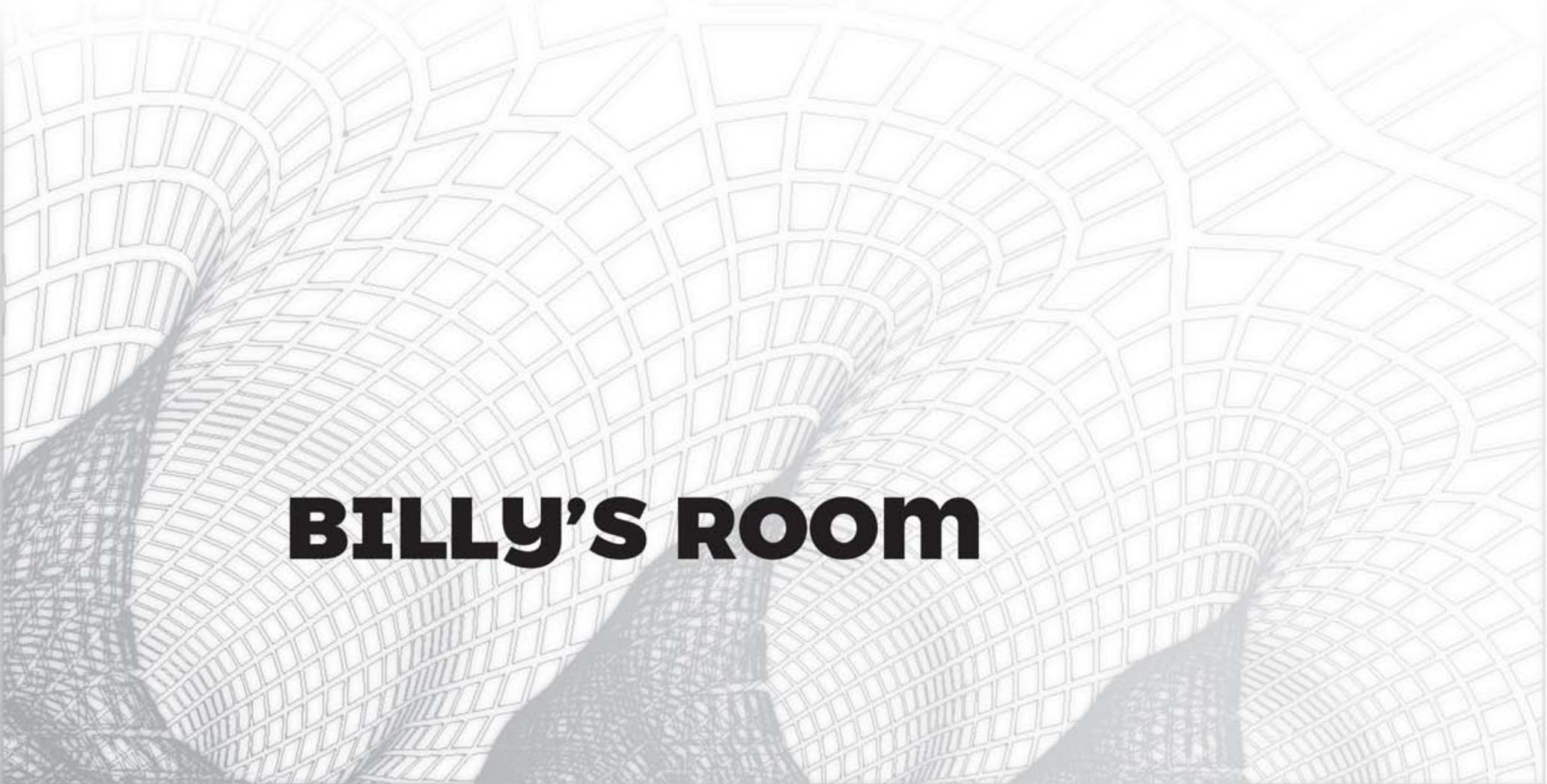




\section{E2. Billy's Room}

The Billy's Room experience focuses on the unique sense of scale VR allows designers to work with. As discussed before, currently, VR offers the closest way for us to emulate the real world in a digital space for users to experience true sense of scale. Therefore, I wanted to create an obvious sense of scale change that the user can experience to show just how effective this can be in creating an immersive environment. From a more technical angle I wanted to figure out a good way to create instances of objects and mirror their properties based on other objects in the game world.

\section{E2.1 Prototype A: Possessing Chess Pieces}

This prototype was just a quick body swap idea I had after a discussion with my supervisor about the position the player takes during a multiplayer VR board game. In traditional chess players would sit across from each other and take turns trying to outwit their opponent. Both players can see the entire field and act as a kind of general directing their army. There have been instances of digital chess where the pieces would be animated and battle each other to add to the immersion of the game, but my supervisor and I imagined there could be added layers when playing chess in VR. So, I designed a basic chess board with the pieces laid out as if there was a game midway being played. The user would be on 


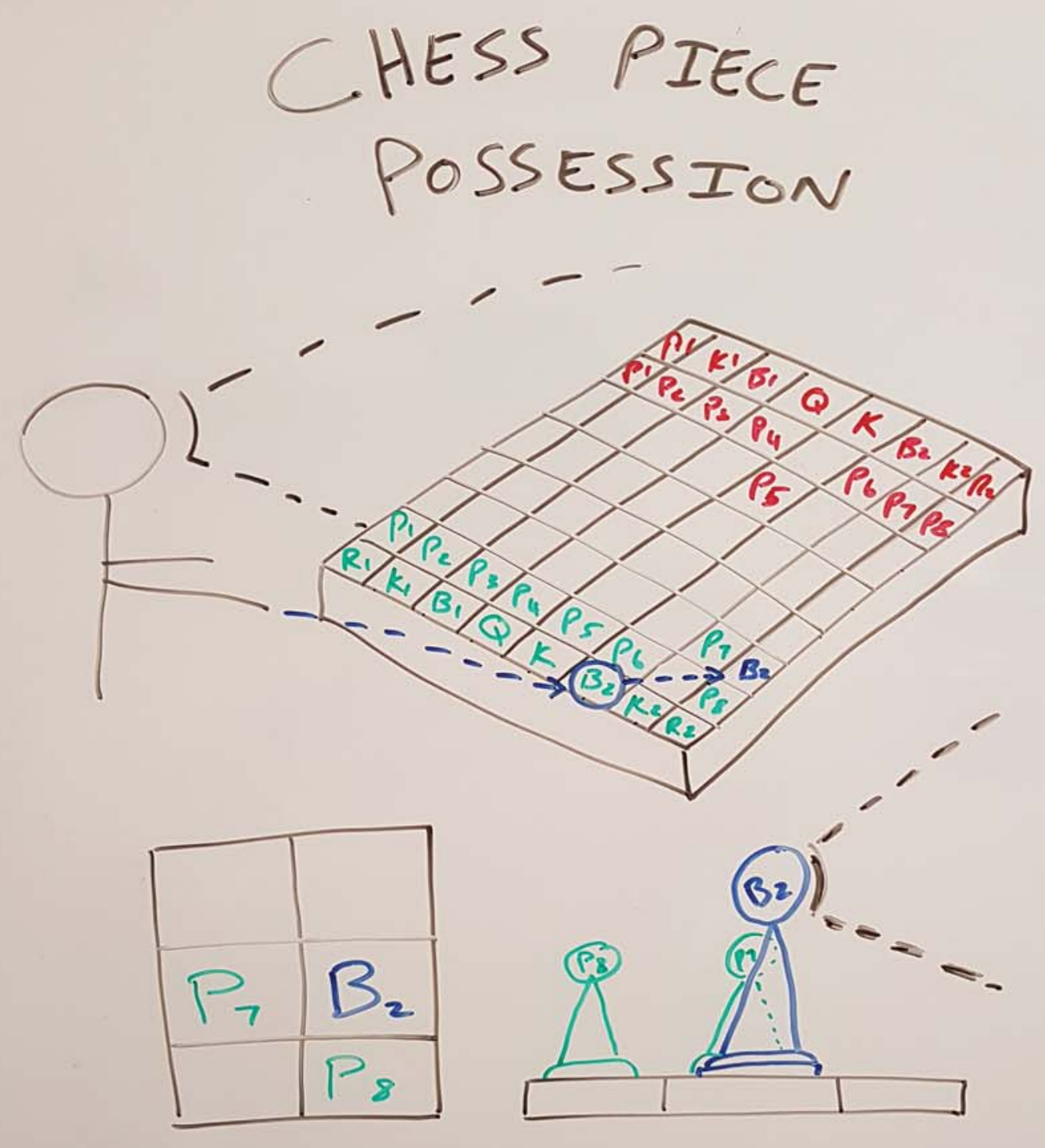

- During active user turn, Camera is attached to Avatar eyes

- During inactive user turn, camera is attached to last placed piece

fig. 7: Chess Piece Possession Prototype planning 
one side of the table looking down over the chess board. At any time, the user could choose a chess piece by touching it and then they would "become" that piece, moving their perspective to that of the piece. This would dramatically change the viewpoint of the player at that time. Ideally, this could add another level of strategy to the game as you would only ever see the entire board when it was your turn and could not see what your opponent has done till after they have made their move.

As an experiment to show the change of scale from small board pieces to suddenly being among them, this was very effective. I would imagine even more so if I added this functionality to a proper multiplayer game where you would be able to see the opponent picking up and moving pieces around you. As multiplayer experiences were outside of the scope of this thesis, I plan to continue exploring this idea in the future.

\section{E2.2 Prototype B: The Clone Pad}

I had an idea of what I wanted to do for the final experiment for scale, so I worked on a small prototype that would be essential to get it working. I wanted to have the user be able to place objects on an area we will call Space A. Then when the user triggered the event, copies of the position (relative to Space A), the model, and orientation of that model would appear on another area, Space B. The difference was that Space B would be $\mathrm{X}$ times larger or smaller than Space A and the calculations would have to take that into account.

To achieve this, I created a small room with two surfaces. On the left most surface there was an empty plane (Space A), one by one meter in 


$$
\begin{gathered}
\text { THE ClONE } \\
\text { PAD }
\end{gathered}
$$

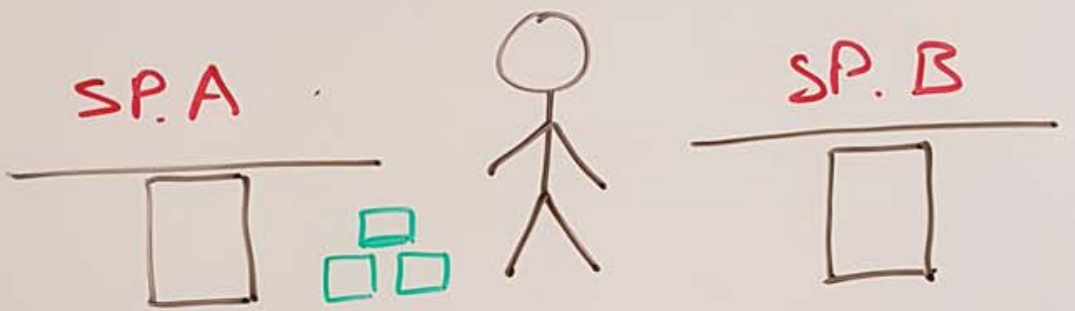

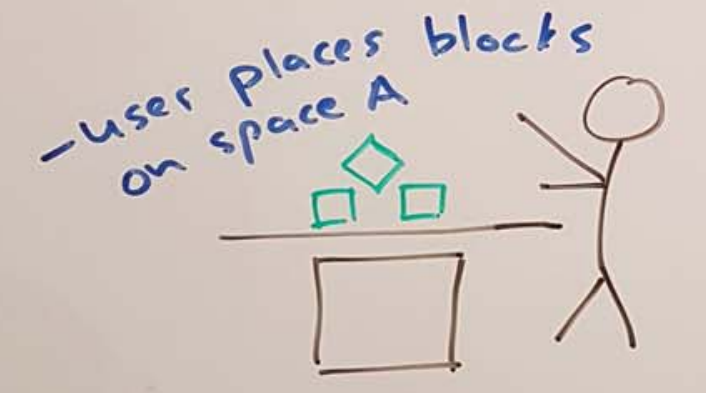

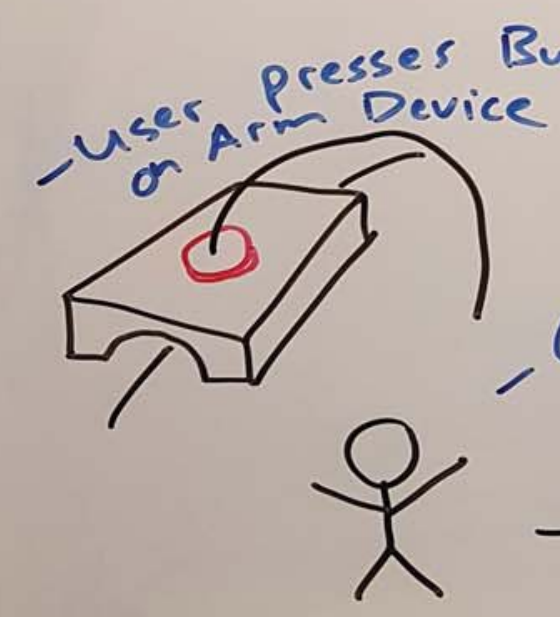

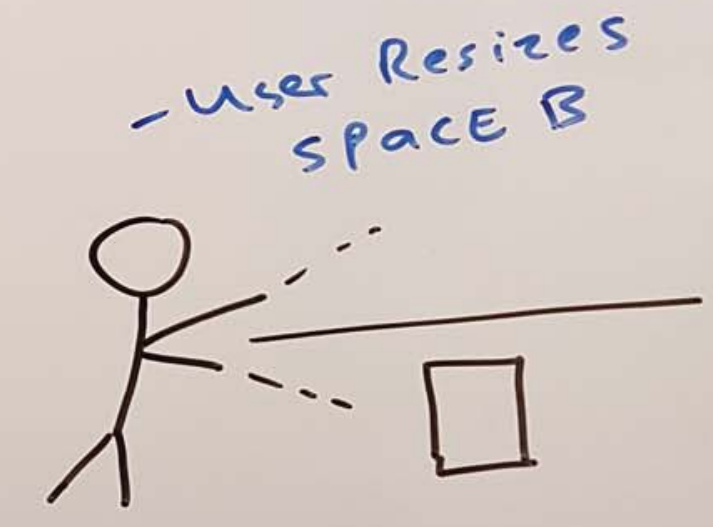

Copies of space $A$ blocks appear space 3<smiles>C[Si](C)(C)[Si]</smiles>

Fig. 8: The Clone Pad Prototype planning 
size. On the floor beside the surface there were several small blocks. The user could pick up and place blocks however they chose onto the plane (Space A). On the right most surface there was a second plane (Space B), that was also one by one meter in size. The user could resize this plane by holding both hands over it, activating the trigger buttons and pulling their hands apart or bringing them together. The plane could be resized up to two by two meters and down to point five by point five meters.

When the user was satisfied with the scene they would press the button on the virtual wrist device on their left arm and the program would calculate where to put the new cubes, resize them and orient them appropriately. 


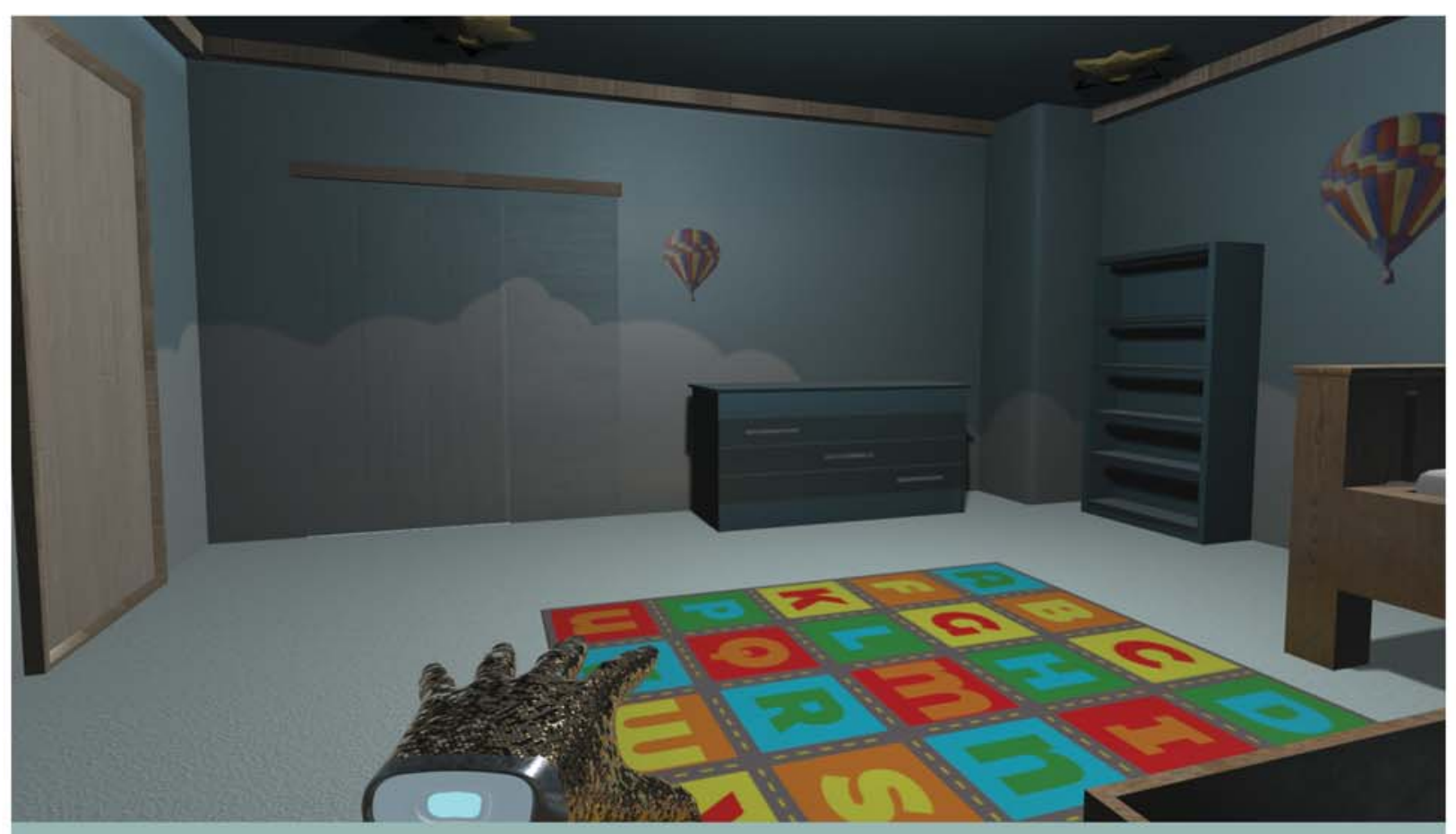

Fig. 9: Billy's Room Interior view 1

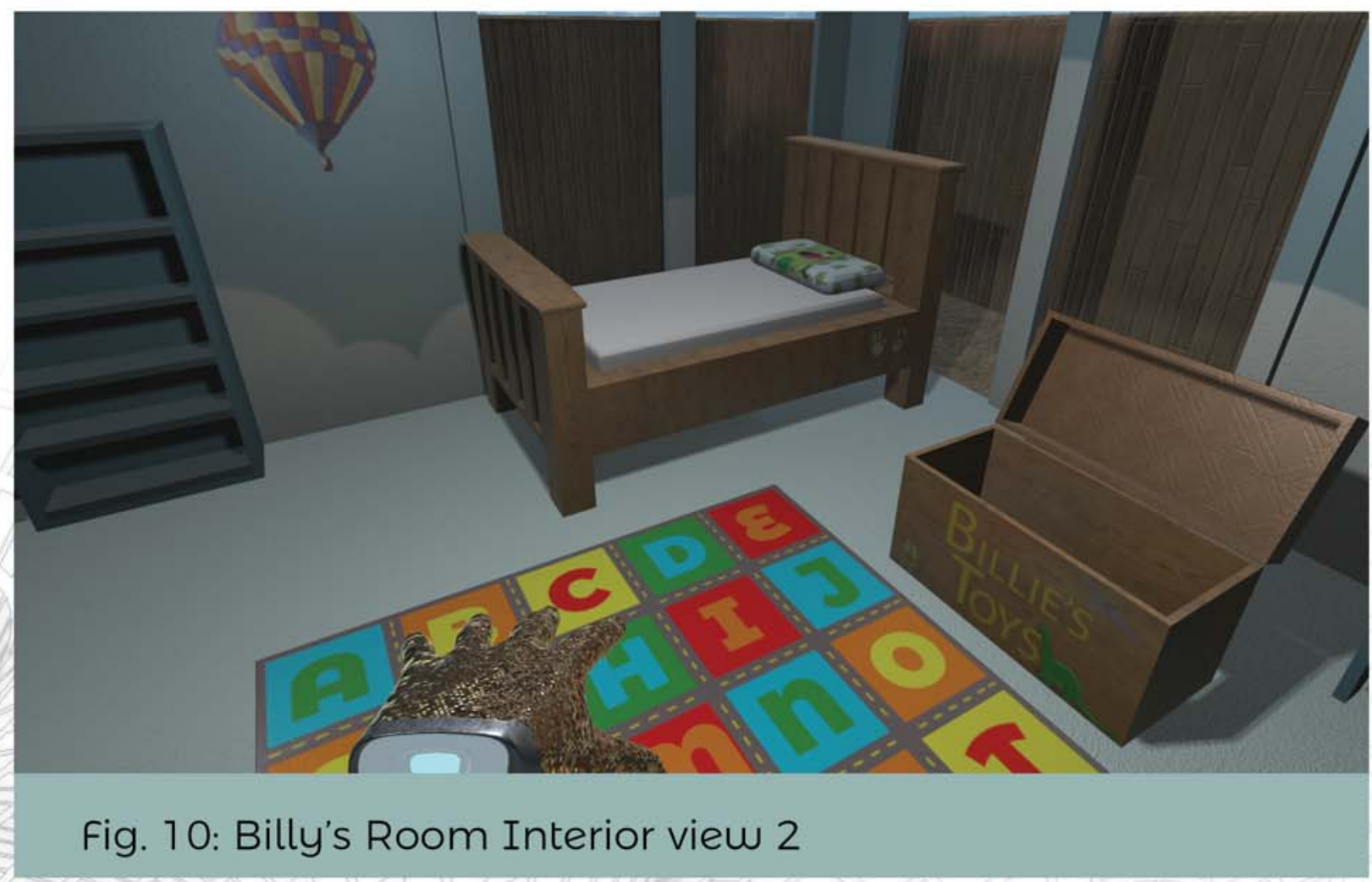




\section{E2.3 The Final Build: Billy's Room}

This experience built upon the Clone Pad prototype. To add to the plot of this experience, I wanted to create the idea of the fantasy world that children have when they play with their toys. I fondly remember building all kinds of structures with my toys and imagining I was walking amongst them.

To achieve this, I created a simple room, with a bed, closet, desk, display stand, toy box, and toy mat on the floor. In the box I put several simple toys I created. When the user starts the experience, they are placed at the centre of the toy mat and can walk on the two by two-meter surface of it. They are limited to that space to begin with as it is more of a static space experience at first. They have access to the toy box and can pick up and place any toys from it on the floor. They can also choose to grab a toy with one hand and if they place their second hand on the held toy they can activate and drag a copy of that toy into their second hand. Once the user has placed the toys how they wish they can activate the button on their wrist device to instantly move them to a space that is two hundred times larger than the toy mat space. Here the user is free to move along the fantasy streets to inspect the toys they have placed up close. I decided on a point and teleport movement system with restricted floor access.

This captures the essence of that childhood game where we pretend to be the characters of the toys we play with amongst our other toys. More importantly it gives the user that awe-inspiring change of scale moment between placing the small toys and seeing them at a large scale. Therefore, I feel Billy's Room to be a successful experience to add to My VRchive. 


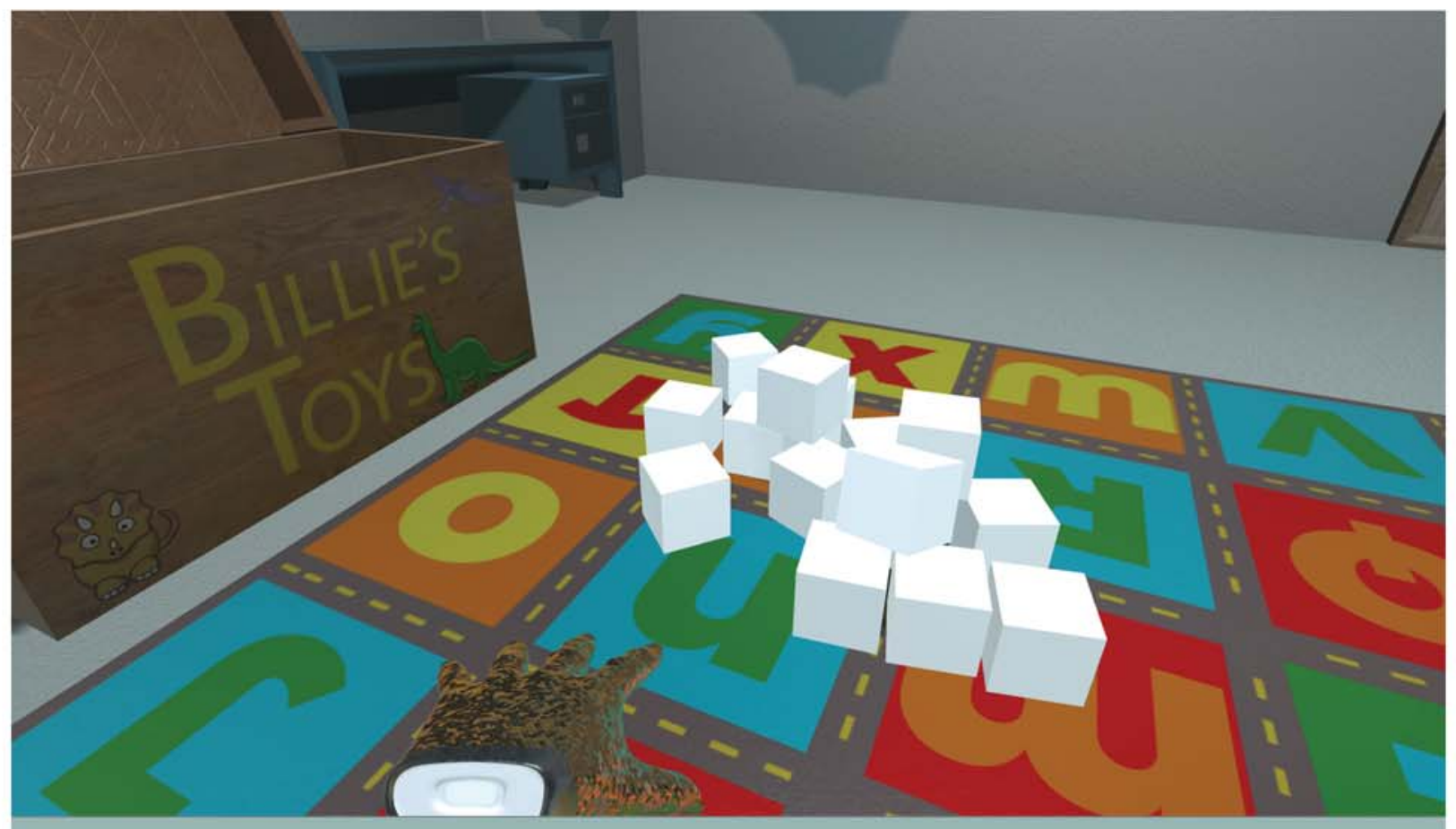

Fig. 11: Toys placed. (White blocks used during development)

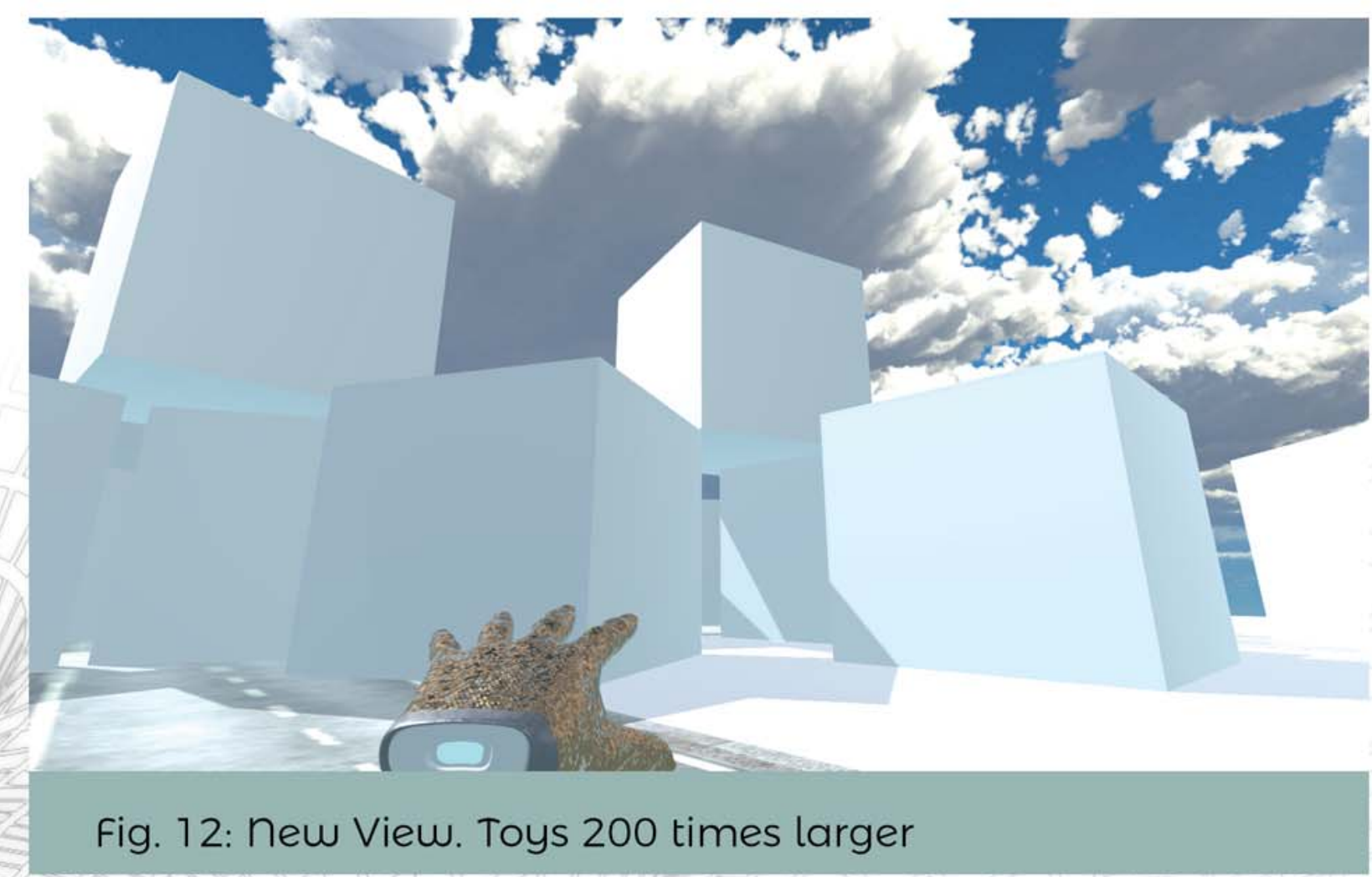




\section{E.2.3.1 Notable Assets}

I kept the assets for the room structure quite low fidelity as they were not the focus of the experience. I tried to keep with a whimsical house in the clouds theme for the wallpaper and colour scheme. This was so that when the user translates to the fantasy world they can see more realistic clouds around them, with the floating air balloon, to further add to the immersion.

The main issue to overcome was that of the scaling toys. I could not just take the smaller toy and scale it two hundred times and place it in the new location as the material for it would look very low quality. The maximum texture map size I was going to use was $4 \mathrm{k}$ and even then, I would have to be careful with how many objects are present in the scene. To achieve higher fidelity larger models, I simply broke down the models into parts and created materials for each part that looked like the smaller model's material. I do warn the user that if they place many objects on the mat, especially the more detailed ones, that some visual lag might occur. This will depend on the strength of the system you are running the experience on and can create visual lag and discomfort. 


\section{E3. The VR Gallery}

The VR Gallery experience started out as a simple location-based teleportation movement experiment with some interaction. One of the issues discussed before was that users can move the camera through boundaries in the world if the level design is not carefully considered. I wanted to try novel ways of solving this problem without interfering with the user's immersion. What follows are the various prototypes I designed and the success and failures from each that ended in me developing the final VR Gallery experience.

\section{E3.1 Prototype A: The floor on a floor}

I decided that I wanted to focus on teleportation movement and investigate how I can use it effectively. When allowing the user to teleport to any section of the floor you can cause potentially unanticipated results. Either the user is "stuck" in a game object or they can see through walls and boundaries by being close enough to them to just stick their head through. If you are a 3D modeller, you will know all too well that we tend to model only the parts of structures we anticipate the user to be able to see at any given time. Therefore, when a user can stick their head through the geometry it can become quite clear where models have no back faces and can potentially break immersion. 
FLOOR ON a FlOOR

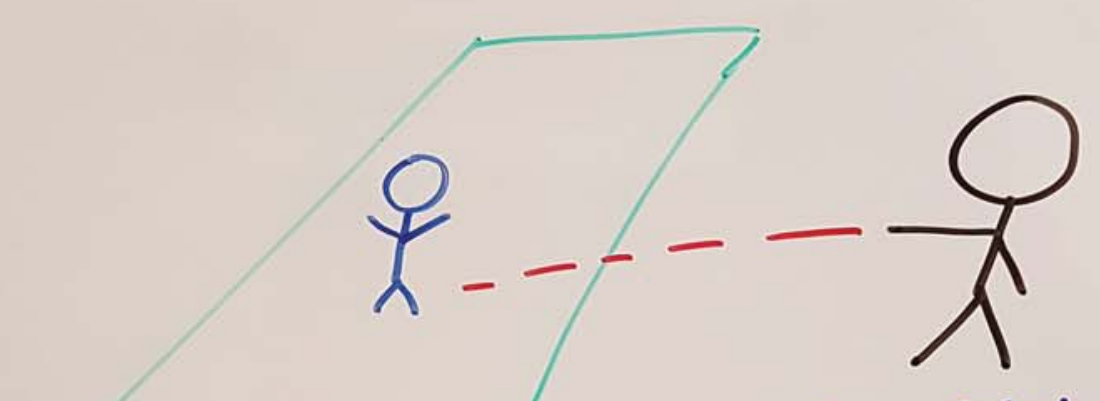

- user can point to any green surface (collider) to instantly move to

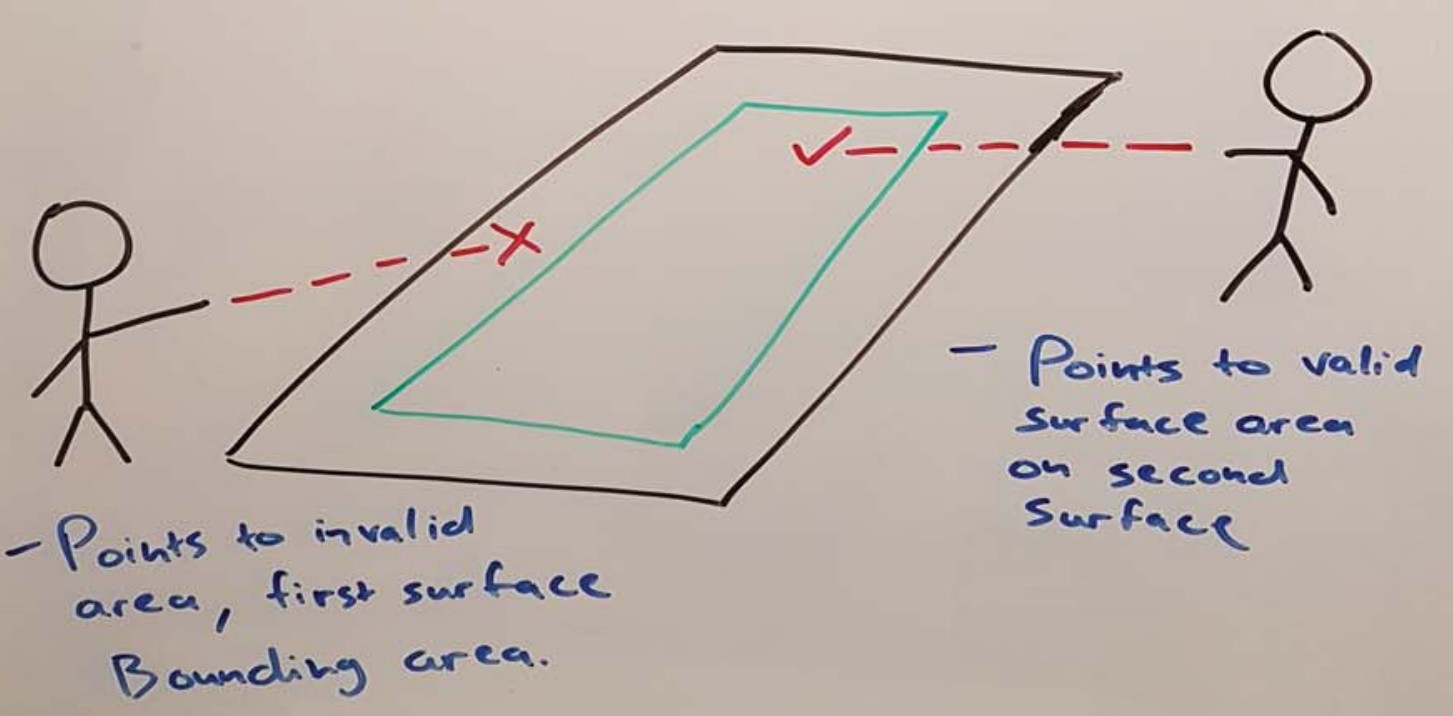

Fig. 13: The floor on a floor Prototype planning 
To prevent this, I developed a simple room with an eight by sixmeter floor. This floor would have a collider that would not cover the entire floor, but only seven by five meters of it. To move around the room the user would point their controller at the floor and press the trigger button. An invisible ray would fire from the end of the controller towards wherever the user was pointing. If the ray would hit the floor's collider the user could let go of the trigger and be moved to that spot. This meant that there would always be at least a meter from the edge of the experience in the virtual world to the user. I found that leaning over a meter to stick my head through was rather difficult, so I was happy with the outcome. I did, however, feel that because there was no clear visual indication as to where you could and could not move before pointing at it potentially confusing.

\section{E3.2 Prototype B: Points of Interest}

Having thought about creating clear visual areas for teleportation, I developed another prototype. This time the user started at the centre of a two by two-meter platform in outer space with three floating platforms in the distance. In front of them was another semi-transparent floating platform which they could point to with the controller to interact with. Depending on where they were standing when they interacted with the semi-transparent platform, the user would be directed to reposition themselves back at the centre of their original platform before they could move to the next. When they were correctly positioned, they could then interact with the semi-transparent platform again. This would then move the user to that new platform instantaneously and the platform would 


\section{POINTS OF INTEREST \\ (NAVIGATION)}

(1)

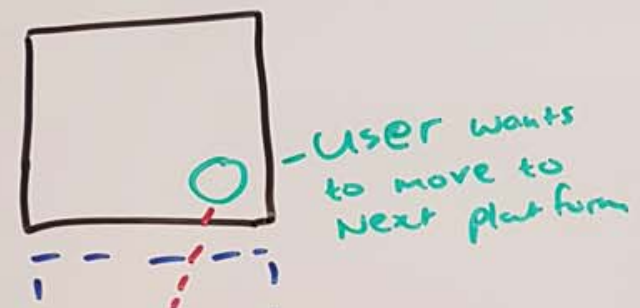

(3)
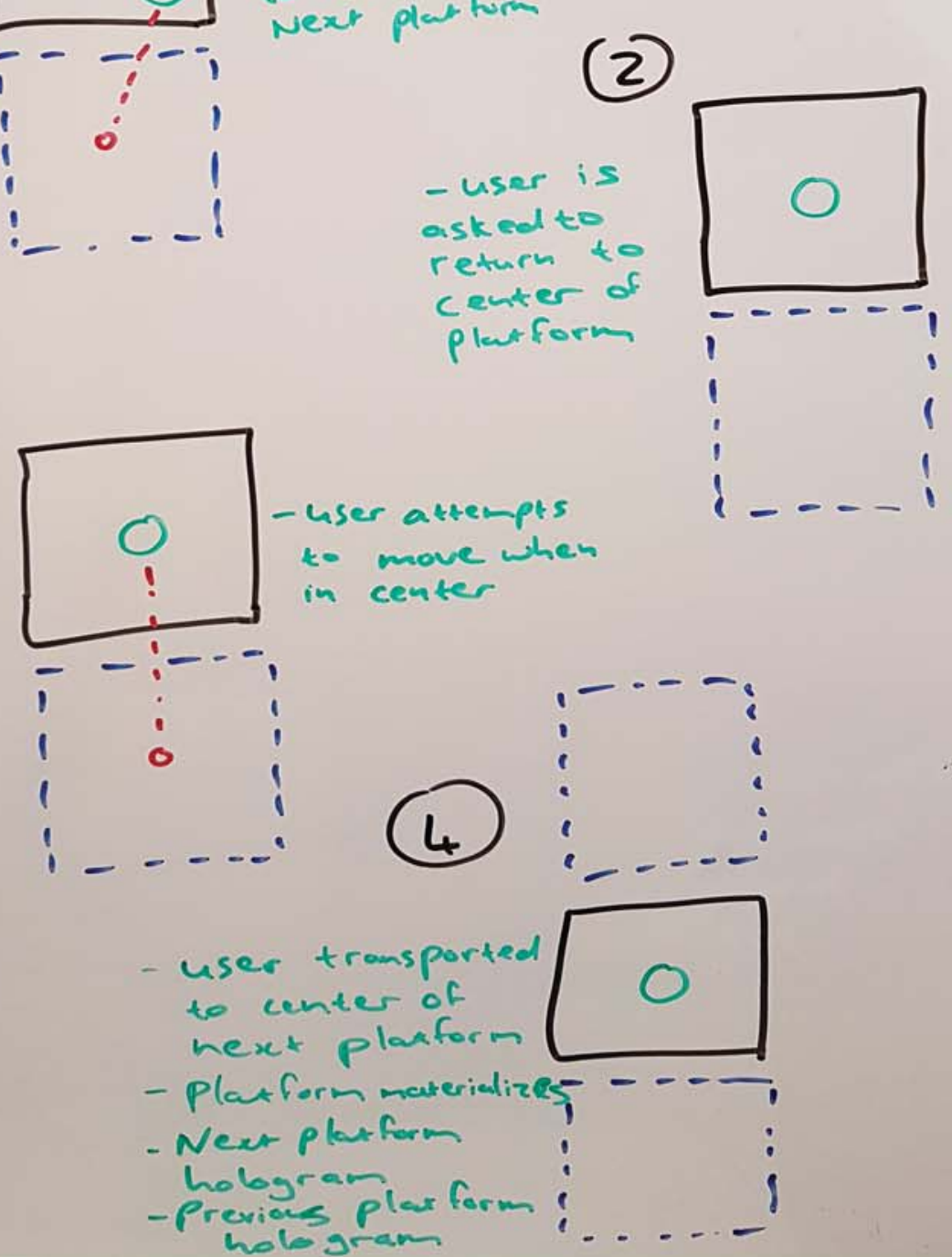

Fig. 14: Points of Interest Prototype planning 
materialize completely. The previous platform would now be semitransparent, and another semi-transparent platform would appear at the opposite end. The user could then move to these in the same way to bridge the gap to the floating platforms, each with an object on them the user could pick up and inspect.

One thing that this type of movement solves is that you can design your experience with a very strict floorspace in mind. Each two by twometer platform corresponds exactly to the two by two-meter area in the real world the user starts on. Therefore, there is no risk of the user walking into anything outside of the boundaries as they would always be asked to return to the real-world centre before they can "move on". The obvious limitation is that it could not be used for very fast paced large area movement experiences for the same reason.

\section{E3.3 Prototype C: The Blackout Wall}

This prototype experiment was to prevent users from sticking their heads through walls and objects in the virtual space. One way I thought was just to have the user's vision become black when they do so. I also wanted to see how it would feel to have their vision taken away instantaneously versus transitionally.

I developed a small prototype where the user was presented with a small four by four-meter room. At the centre of the room was a table and the room had standard four walls, a ceiling, and a floor. The entire floor was available to move around on using the point and teleport method. I then wrote a script that would send an invisible ray from the user's game 
camera (or eyes in the experience) to the four walls, the table and the roof. When the length of any of those rays were too small I would simply make the screen black. This was done immediately at first. After finding it was quite a jarring experience as there was no warning of this, I then created a black overlay that would start out invisible but become more visible in a vignette pattern as the user got closer to those boundaries. This felt a lot more acceptable as an experience as the user is given visual feedback that putting their face too close to something has a negative effect. 



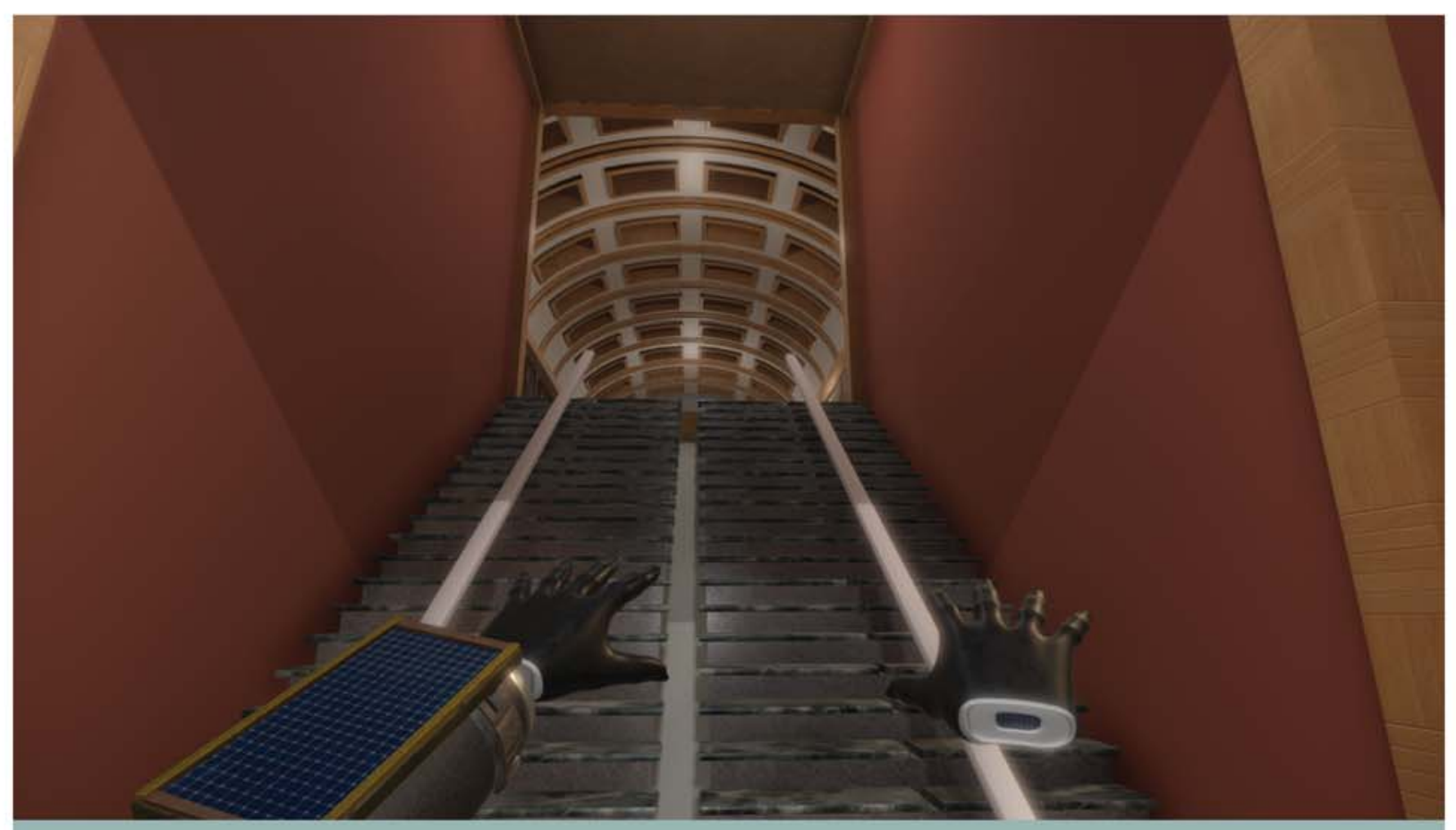

Fig. 16: The V-Art Gallery lobby stairs to the art floor.

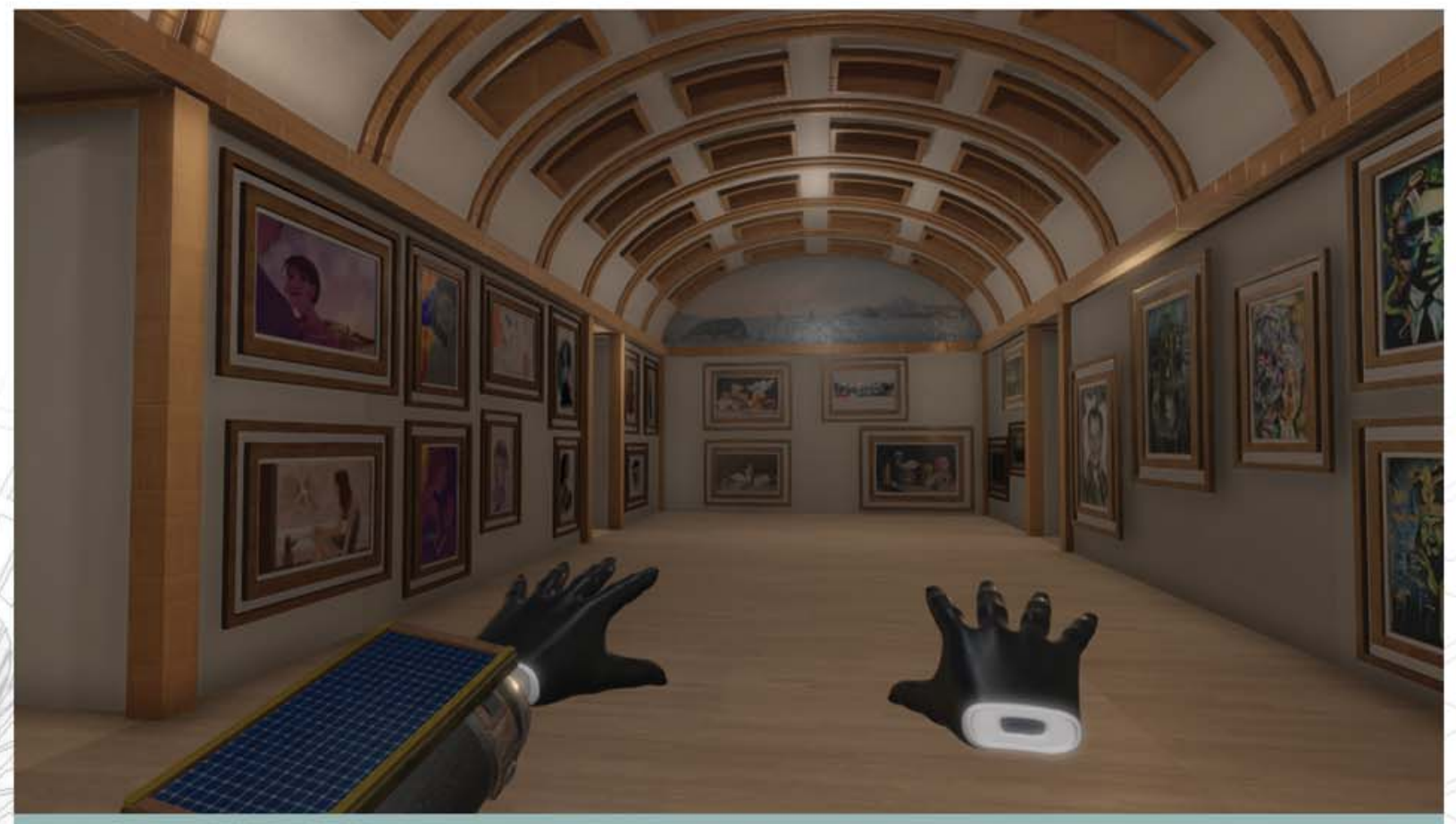

Fig. 17: The art floor 


\section{E3.4 The Final Build: The VR Gallery}

I wanted to combine elements that were successful from each of those prototypes for my final My VRchive entry for navigation. However, I needed to set a scene first. I remembered a project I had worked on a while back where I wanted to bring museum content to life in Virtual Reality. The museum goer could inspect rare and valuable objects up close without having to touch the physical objects, as most objects in a museum are off limits to this.

Therefore, I set out to create a gallery space that would have a main corridor with four separate rooms. The main corridor would have paintings on the walls and each room would have a large statue for the user to see. When a user pointed at any of the paintings or a statue, a holographic replica would appear on their arm device and they would be able to "pull out" a copy of it to look at closer without having to "touch" the original.

To move around the space, users will use the point and teleport method used in prototype 2, meaning they need to stay at the centre of the real-world space to move to new squares in gallery space. Just like the boundaries you might find around real exhibitions, I created a boundary that, when the user comes too close, will activate and warn them to not get closer. For now, there is no repercussion for doing so, but one could easily add gamification elements to that.

Arguably, none of those objects are real and there really is no point in not being able to touch them, so why have this feature? Going back to what we discussed about immersion, I propose that this is part of the plot 


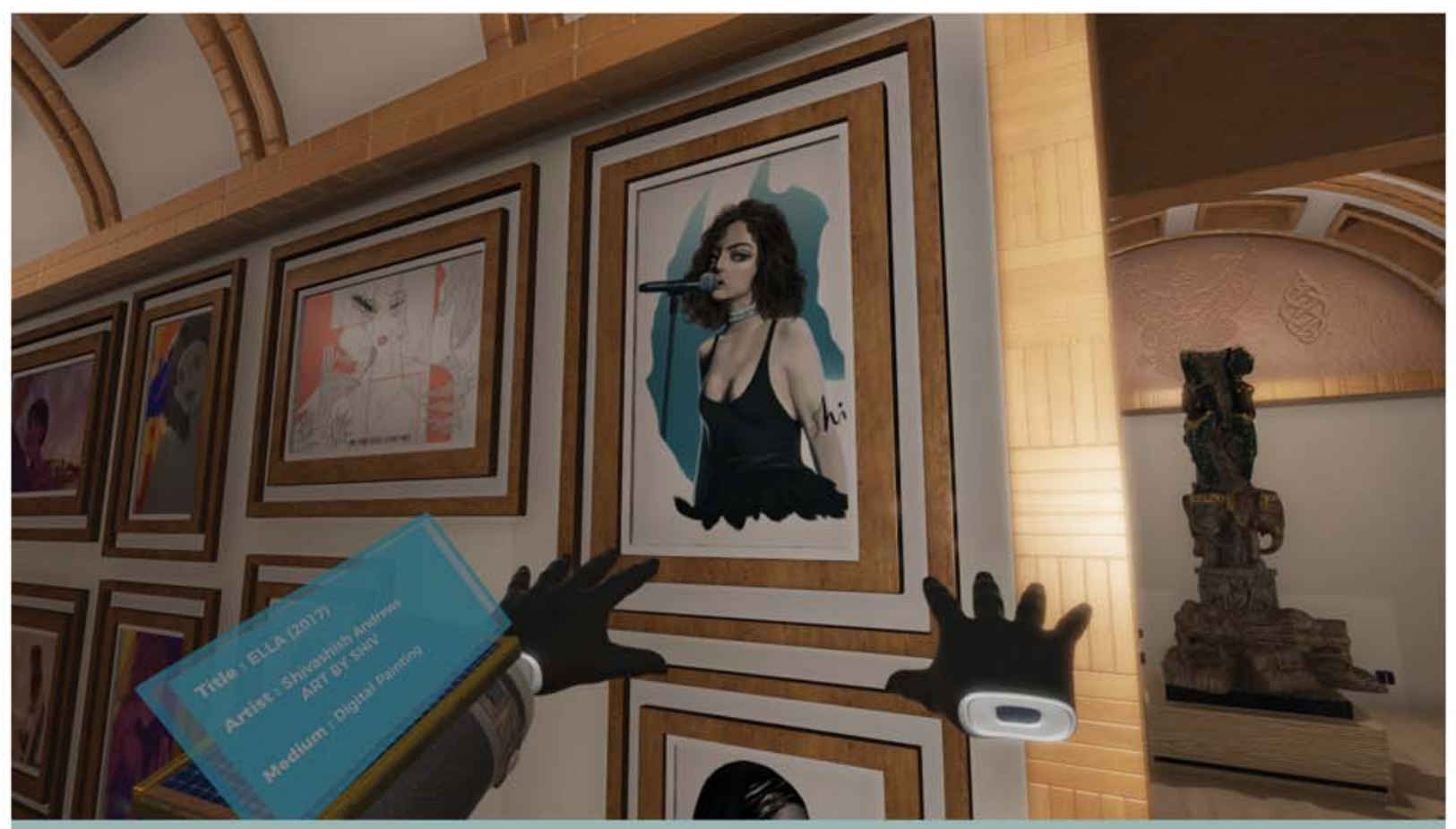

Fig. 18: Interacting with painting. Artwork information

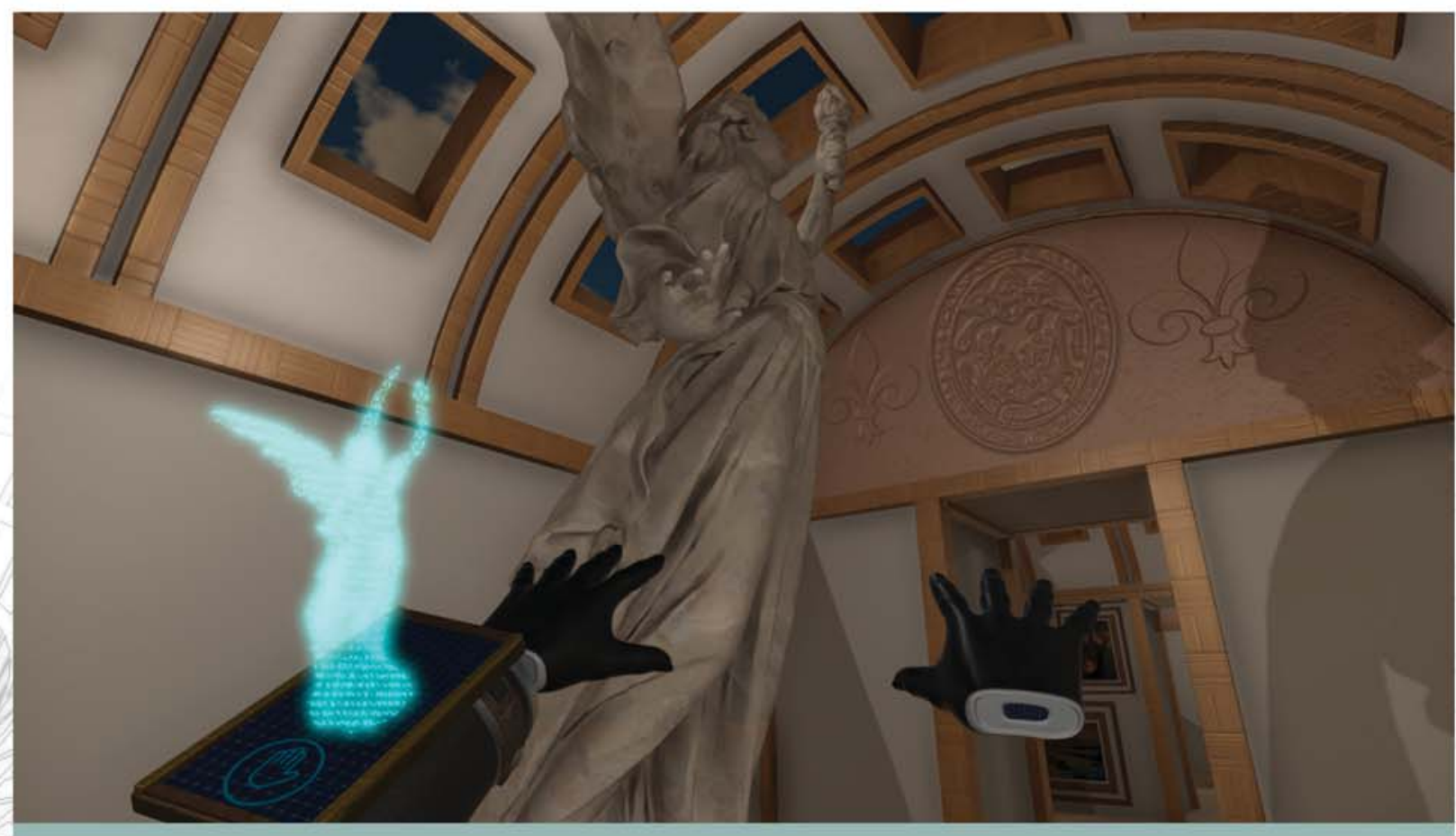

Fig. 19: Interacting with the Statue. Cloning hologram 
or story of the experience. It is the real world transitional moment that I theorise is so important when developing VR experiences. In a real museum or exhibition space you are not usually allowed to touch the pieces on display. It would, however, be much more immersive an experience if you could handle the works and look at them up close without damaging them. I feel this kind of experience satisfies that curiosity.

\section{E3.4.1 Notable Assets}

To achieve the feel of an exhibition space in a museum I went through several design iterations. Initially I created a very heavily Victorian inspired environment with marble floors, intricate windows and door frames etc. There was also a domed ceiling with a large painting across it. Even though these assets took a long time to build and individually I was pleased with them, when I looked at them in VR the scene was very busy and distracting. Furthermore, it would take too long to adequately arrange the interior to look right and interior decoration is not my strong suit. I did not want this to break immersion, so I opted instead for a cleaner look.

A simpler wooden floor and mono-coloured wall made certain the artworks and pieces were the focus, with only some wooden trim along the edges. I created two types of frames, a landscape and portrait style one and covered the walls outside of the sculpture areas with them. Several artists were kind enough to allow me access to some of their work to display and I feel this created a much richer experience than the open 


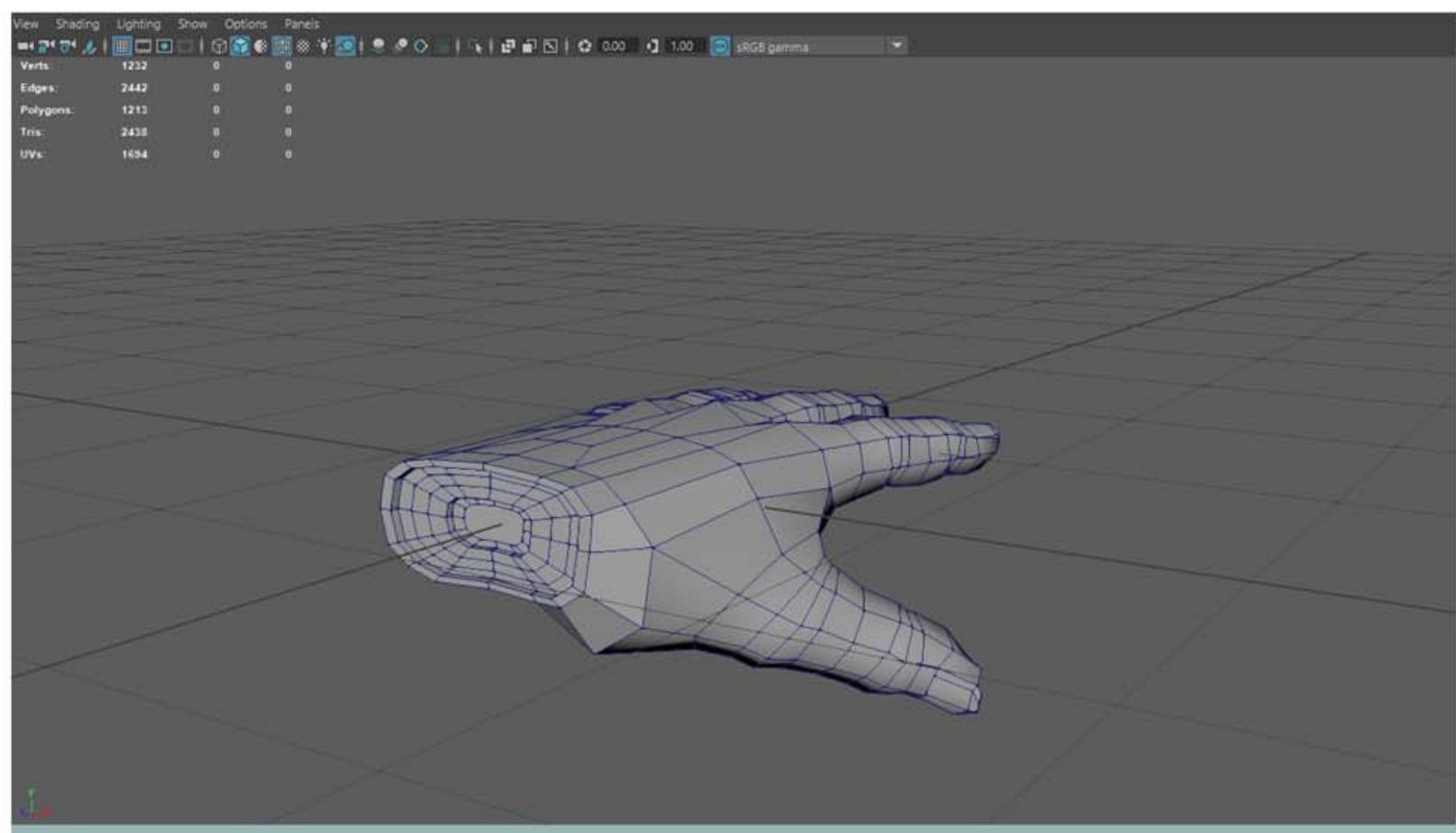

Fig. 20: Creating the VR Hand model

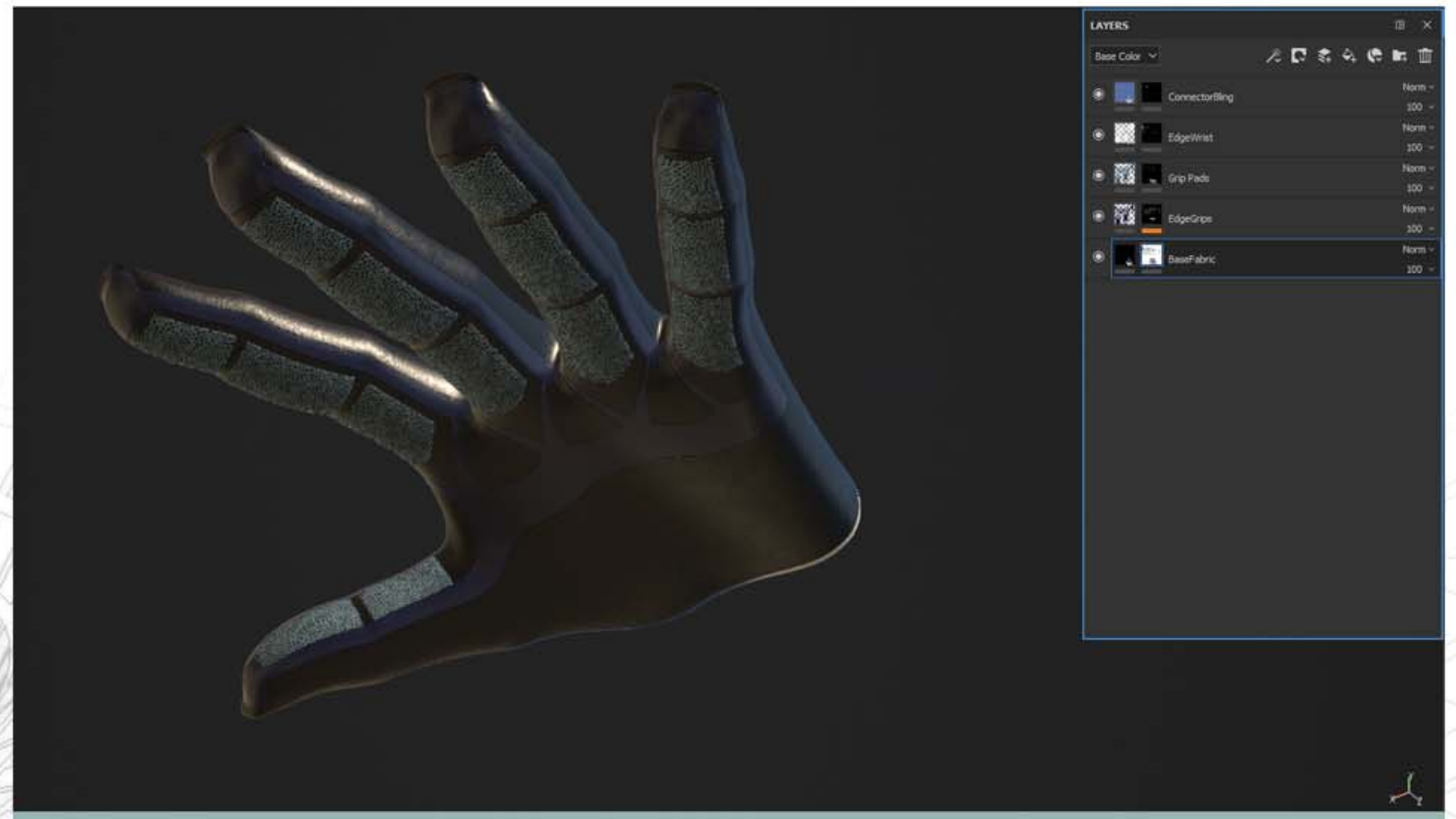

Fig. 21: Creating the texture maps for the VR Hands 
source Victorian era paintings I had used before. All these artists have given me permission to use their work and I have given them credit both in the experience and in this thesis.

I did end up keeping a domed roof, but I instead opted to create windows along the panels, so the user can see the clouds outside, creating a much more serene environment.

Lastly, for the four sculptures, I used 3D scans provided by the Stanford University Computer Graphics Laboratory. These models were of incredibly high resolution, so I had to lower their fidelity in Maya and export them as FBX files to be used in Unity. I made sure to not alter the models' overall shape, so they are still recognizable from their original scans. I did take some artistic license and created materials for them using Substance Painter.

The arm device for this experience has two purposes. First, it lets the user create copies of the sculptures to look at up close. Secondly, when interacting with the paintings, a panel appears on it that gives the user more information about the piece and the real artist.

The hand was modelled by me in Maya LT. I wanted to create animations for the various states, but that proved to be outside of the scope of my assets generation time allowance. Instead, I opted for making static instances of the hand movements that would activate when the user pressed a specific button. 


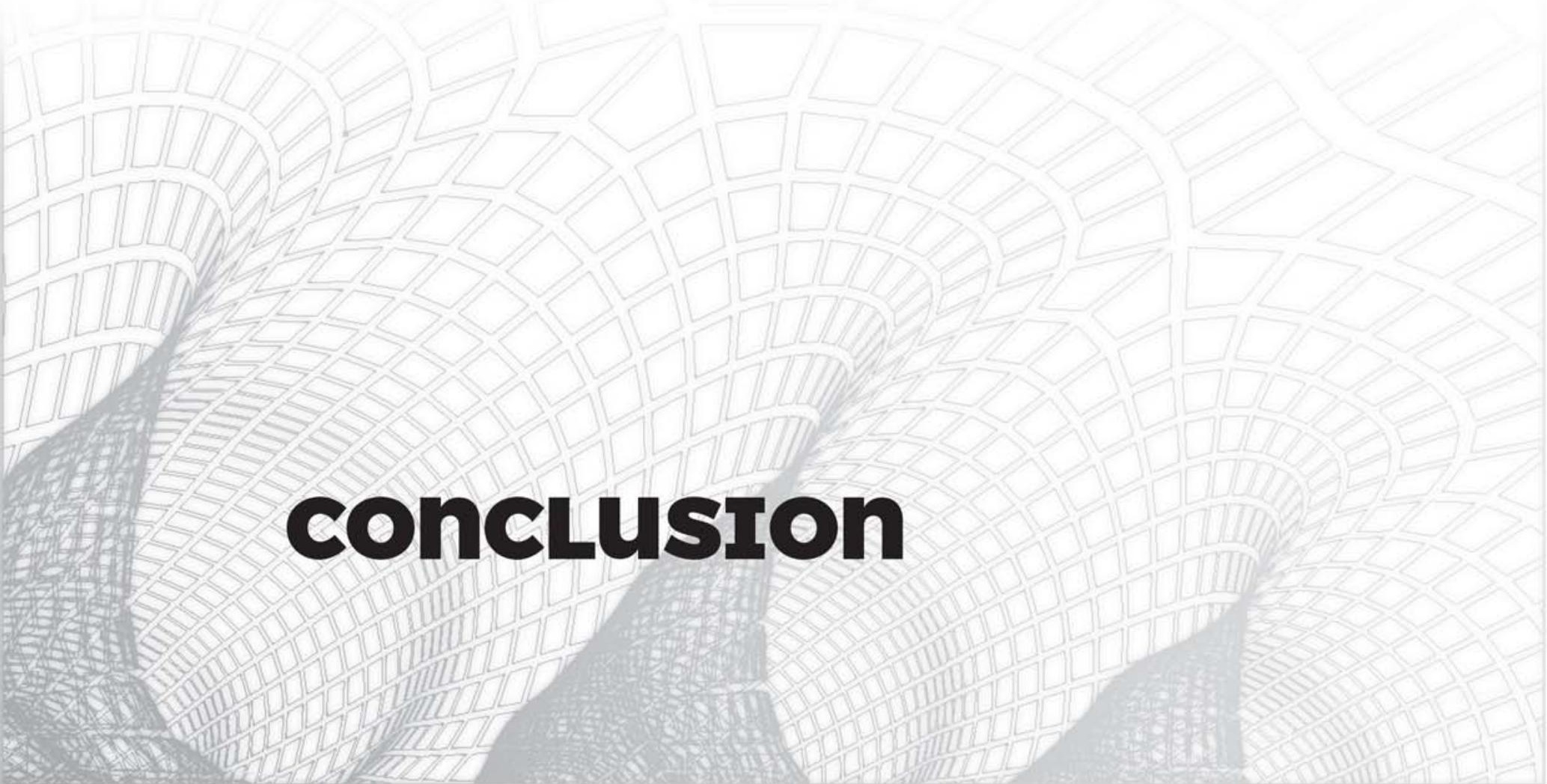




\section{Conclusion}

This thesis explained the importance of developing a unifying methodology for designing content and interaction for Virtual Reality gaming by using real world precedents. Drawing inspiration from interaction and historical research into board and table top gaming, I combined this with past and present design thinking of both Virtual Reality experiences and core game design methodology. This allowed me to develop a series of experiences to be added to a library of knowledge I can further add to and share. Encouraging other Virtual Reality content and game designers to do the same would mean faster development toward a unifying methodology for creating meaningful immersive experiences for Virtual Reality.

The first experiment, Element Room, focussed on object interaction. The player would be presented with an octagonal room that had seven element problems on the walls around them to solve and a single wall with a periodic table. The player would then choose elements from the periodic table that would then cause cubes of that element to appear on the floor around them. From there they would have to pick those cubes up and combine them, in order, to the chemical equations on the walls to form the desired compounds. When a compound is complete, that wall section would reveal a hidden object. Once all puzzles are complete, the user is presented with a lever to take them back to the My VRchive station. 
My biggest challenge with this experience was to relay information to the user through the arm device. Some users found the text difficult to read initially, so to achieve the desired result I had to go through many different versions. The final game element was fun and educational, something I would like to explore further in the future.

The second experience, Billy's Room, was an experiment with sense of scale. The player would find themselves standing on a playmat inside a child's room. To the one side would be a box filled with Billy's toys. The player can pick up and place these toys on the mat around them. The player would also be able to, when holding a toy, touch the toy with their other hand and pull apart to create a replica of that toy. Once the player is happy with the arrangement on the floor, they would then press the button on their arm device to transport them to a large-scale version of the toy mat (essentially shrinking them down two hundred times smaller). From there the player can move around and inspect the scene they created from this different perspective. Even though the fidelity of all the items in this scene was not that high, I am happy with the sense of scale change this created. Going from inspecting a toy in your hand to being able to walk around it is a truly exciting experience.

Explaining the scenario to players in the experience was once again tricky. I attempted to use world space user interface panels instead of the arm device in this one. This allowed me to give the player more information with less slides. 
The third experience, The VR Gallery, was an experiment on movement around the VR space. The player would find themselves in the lobby of a small art gallery, beckoned by two sets of stairs. Once up the stairs the player would be able to move from floor segment to floor segment to inspect the art around the space. Whenever a player wanted to move to the next segment, they had to return to the centre of their current segment. This prevented players from walking into anything in the real world, but also limiting their ability, somewhat, from walking through walls and into objects in the Virtual World. At first the constraint took some getting used to, but because of the setting, most people understood the need for it. I feel when using this kind of node-based room scale teleportation movement system, designers would need to have a strong justification for it and could be a good way to explore museums or similar experiences.

To house all these experiences, and those that follow, I developed an entry space called My VRchive. The final iteration of this experience is a simple room with no interaction points. Using the arm device activates the menu system from where you can choose which experience you would like to have a look at. The idea is that each designer customizes their archive to their taste and interaction style. Some might like a Victorian library with books on the walls while others might like an underwater scenario with floating bubbles holding the experiences. 


\subsection{Looking forward}

Currently there are many ways to build VR experiences, which seem to be growing rapidly with the technology advancing daily. With 360 video, gaming experiences, to even virtual tours of potential real estate

investments, it is becoming increasingly more important that we develop a universal methodology for VR to make it easier for future designers as well as minimize discomfort for users in VR.

One area that needs attention, and something I will be working on next, is the multi-user side of VR experiences. As exciting as interacting with things and being awed by the sense of scale of the world you are in, experiencing that with other people brings VR to a whole new level. Of course, with that comes a whole new set of challenges that was unfortunately out of the scope of this thesis.

This thesis investigated only a few things possible when designing for VR and is meant as a stepping stone for me towards adding more experiences to my archive. It is also meant as a different perspective for other VR designers to consider doing the same thing. I feel that if we share as much of what we find into researching real world interaction and translating that to VR, we will soon be able to say we know how to design for VR without having to make things up as we go along.

I hope that designers of VR experiences and games will consider adopting this approach and I look forward to sharing more of my findings soon. 



\section{Bibliography}

Agarabi, M., Bonato, P., \& De Luca, C. J. (2004). A sEMG-based method for assessing the design of computer mice (Vol. 3, pp. 2450-2453).

Alsina-Jurnet, I., Gutiérrez-Maldonado, J., \& Rangel-Gómez, M.-V. (2011). The role of presence in the level of anxiety experienced in clinical virtual environments. Computers in Human Behavior, 27(1), 504-512.

Anderson, P. L., Price, M., Edwards, S. M., Obasaju, M. A., Schmertz, S. K., Zimand, E., \& Calamaras, M. R. (2013). Virtual reality exposure therapy for social anxiety disorder: A randomized controlled trial. Journal of Consulting and Clinical Psychology, 81(5), 751-760.

Beat Saber on Steam. (n.d.). Retrieved July 11, 2018, from https://store.steampowered.com/app/620980/Beat_Saber/

Bell, R. C. (1979). Board and Table Games from Many Civilizations. Courier Corporation.

Brass Tactics. (n.d.). Retrieved July 11, 2018, from http://www.hiddenpath.com/game/brass-tactics/

Cook, C. J., \& Kothiyal, K. (1998). Influence of mouse position on muscular activity in the neck, shoulder and arm in computer users. Applied Ergonomics, 29(6), 439-443.

Cukor, J., Gerardi, M., Alley, S., Reist, C., Roy, M., Rothbaum, B. O., ... Rizzo, A. (2015). Virtual Reality Exposure Therapy for Combat-Related PTSD. In E. C. Ritchie (Ed.), Posttraumatic Stress Disorder and Related Diseases in Combat Veterans (pp. 69-83). Springer International Publishing.

Echo VR. (n.d.). Retrieved July 11, 2018, from https:/www.oculus.com/experiences/rift/1369078409873402/

Fuchs, P., Moreau, G., \& Guitton, P. (2011). Virtual Reality: Concepts and Technologies. CRC Press. 
Gianluca, M. (2010). Metaplasticity in Virtual Worlds: Aesthetics and Semantic Concepts: Aesthetics and Semantic Concepts. IGI Global.

Gobet, F., Retschitzki, J., \& de Voogt, A. (2004). Moves in Mind: The Psychology of Board Games. Hove, UNITED STATES: Taylor \& Francis Group.

IJsselsteijn, W. A., de Kort, Y. A. W., \& Haans, A. (2006). Is This My Hand I See Before Me? The Rubber Hand Illusion in Reality, Virtual Reality, and Mixed Reality. Presence: Teleoperators and Virtual Environments, 15(4), 455-464.

Indie Devs, Not AAA Studios, Dominate Steam's VR Games Chart. (n.d.). Retrieved July 11, 2018, from http://nwn.blogs.com/nwn/2018/07/vrsteam-indie-studios-job-simulator-.html

Jerald, J. (2015). The VR Book: Human-Centered Design for Virtual Reality. Morgan \& Claypool.

Khaliq, I., \& Purkiss, B. (2015). A study of interaction in idle games perceptions on the definition of a game. In 2015 IEEE Games Entertainment Media Conference (GEM) (pp. 1-6).

Lamson, R. J. (1997). Virtual therapy: prevention and treatment of psychiatric conditions by immersion in virtual reality environments. Montréal: Polytechnic International Press.

Linowes, J. (2015). Unity Virtual Reality Projects. Packt Publishing Ltd.

Master List of All of the Upcoming and Released AAA Caliber VR Games. (2018, June 18). Retrieved July 11, 2018, from https://www.vrandfun.com/master-list-of-all-of-the-upcoming-aaa-calibervr-games/

Mine, M. R., Brooks, F. P., \& Sequin, C. H. (1997). Moving objects in space: exploiting proprioception in virtual-environment interaction (pp. 19-26). ACM Press. 
Murray, H. J. R. (1952). A History of Board-games Other Than Chess (First Edition edition). Oxford: Oxford University Press.

Parlett, D. (1999). Oxford History of Board Games. Oxford; New York: Oxford University Press.

Plouzeau, J., Paillot, D., Chardonnet, J.-R., \& Merienne, F. (n.d.). Effect of proprioceptive vibrations on simulator sickness during navigation task in virtual environment, 7.

Robo Recall. (n.d.). Retrieved July 11, 2018, from https://www.epicgames.com/roborecall/en-US/home

Ruddle, R. A., Payne, S. J., \& Jones, D. M. (1999). Navigating LargeScale Virtual Environments: What Differences Occur Between HelmetMounted and Desk-Top Displays? Presence: Teleoperators and Virtual Environments, 8(2), 157-168.

Schell, J. (2014). The Art of Game Design: A Book of Lenses, Second Edition. A K Peters/CRC Press.

Slater, M., Usoh, M., \& Steed, A. (1995). Taking steps: the influence of a walking technique on presence in virtual reality. ACM Transactions on Computer-Human Interaction, 2(3), 201-219.

Star Trek ${ }^{\mathrm{TM}}$ : Bridge Crew on Steam. (n.d.). Retrieved July 11, 2018, from https://store.steampowered.com/app/527100/Star_Trek_Bridge_Crew/

Tabletop Simulator on Steam. (n.d.). Retrieved July 11, 2018, from https://store.steampowered.com/app/286160/Tabletop_Simulator/

The Notorious Board Game That Takes 1500 Hours to Complete. (2017, September 19). Retrieved July 10, 2018, from https://www.kotaku.com.au/2017/09/the-notorious-board-game-thattakes-1500-hours-to-complete/ 


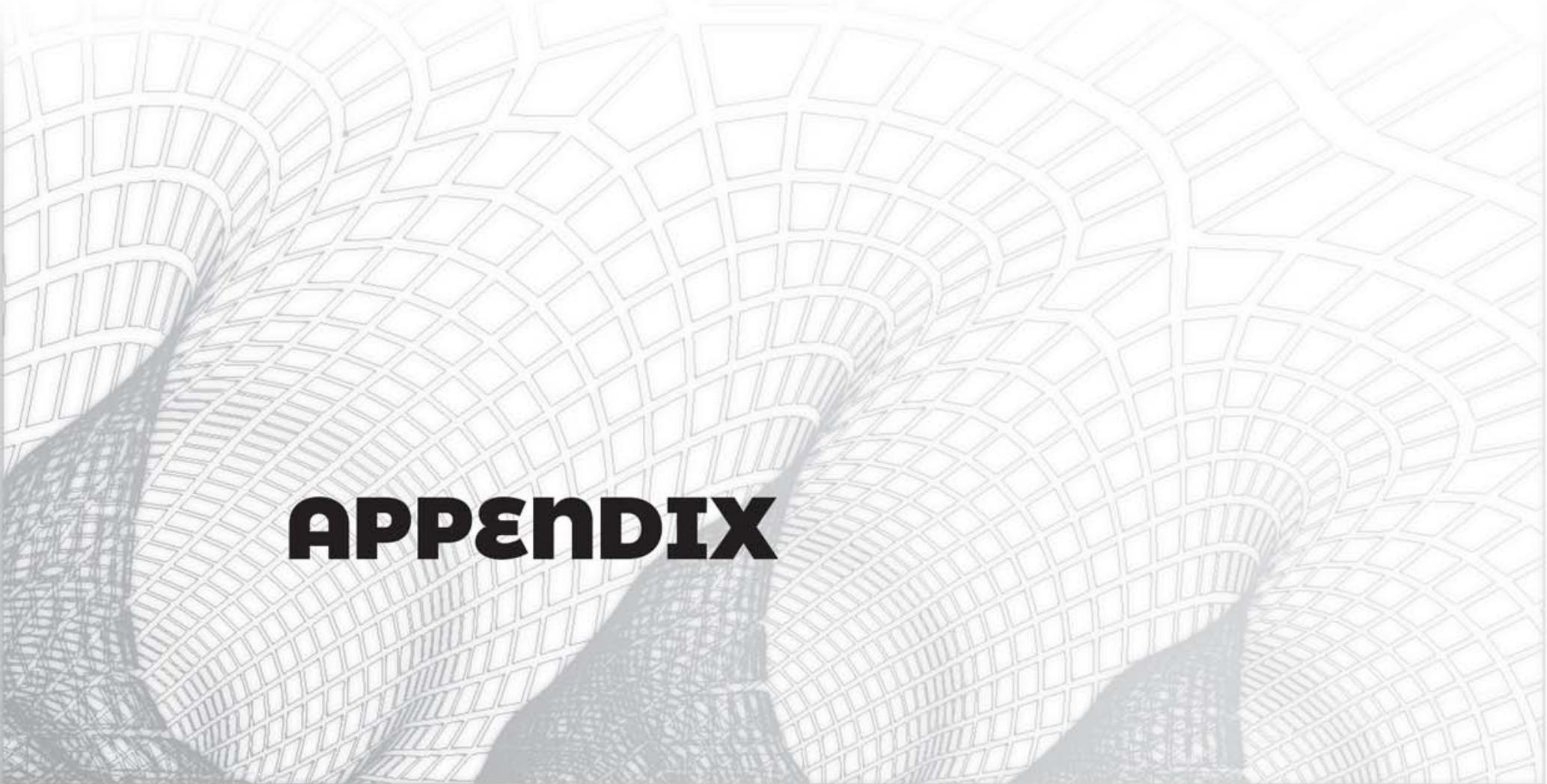




\section{Appendix}

\section{$\underline{7.1 \text { Artist Contributions }}$}

I would like to personally thank the following artists, in no particular order, for contributing their work to make the Art Gallery scene more immersive.

Anna Gan

Chris Brown - ParatopicTeam

Fiona Bowden - Fiona Bowden Creations

Jaco Klopper - JK Dreams Photography

Marike de Villiers - Marike Kleynscheldt Art

Nicola Yeo

Ryan Case - Sink or Swim Art Gallery

Shivashish Andrews - ART BY SHIV

\subsection{Other Credits}

Special thank you the Stanford Computer Graphics Laboratory for making available the following models I used in the Gallery experience:

\section{Happy Buddha}

\section{Dragon}

\section{Lucy}

\section{Thai Statue}

